\title{
Robotic Follow-up for Human Exploration
}

\author{
Terrence Fong ${ }^{1}$, Maria Bualat ${ }^{1}$, Matthew C. Deans ${ }^{1}$, Byron Adams ${ }^{2}$, Mark Allan ${ }^{1}$, \\ Martha Altobelli ${ }^{3}$, Xavier Bouyssounouse ${ }^{1}$, Tamar Cohen ${ }^{1}$, Lorenzo Flückiger ${ }^{1}$, \\ Joshua Garber ${ }^{4}$, Elizabeth Palmer ${ }^{5}$, Essam Heggy ${ }^{6}$, Mark Helper ${ }^{3}$, Kip V. Hodges ${ }^{2}$, \\ José M. Hurtado, Jr. ${ }^{7}$, Frank Jurgens ${ }^{8}$, Tim Kennedy ${ }^{8}$, Linda Kobayashi ${ }^{1}$, Rob \\ Landis $^{1}$, Pascal Lee ${ }^{1}$, Susan Y. Lee ${ }^{1}$, David Lees ${ }^{1}$, Jason Lum ${ }^{9}$, Mike Lundy ${ }^{1}$, Tim \\ Shin $^{3}$, Tod Milam ${ }^{10}$, Estrellina Pacis ${ }^{9}$, Eric Park ${ }^{1}$, Liam Pedersen ${ }^{1}$, Debra Schreck- \\ enghost ${ }^{10}$ Trey Smith ${ }^{1}$, Vinh To ${ }^{1}$, Hans Utz $^{1}$, Dawn Wheeler ${ }^{1}$, \& Kelsey Young ${ }^{2}$ \\ ${ }^{1}$ NASA Ames Research Center, Moffett Field, CA \\ ${ }^{2}$ Arizona State University, Tempe, AZ USA \\ ${ }^{3}$ University of Texas, Austin, TX, USA \\ ${ }^{4}$ University of California, Davis, CA, USA \\ ${ }^{5}$ Case Western Reserve University, Cleveland, OH, USA \\ ${ }^{6}$ Jet Propulsion Laboratory, Pasadena, CA \\ ${ }^{7}$ University of Texas, El Paso, TX, USA \\ ${ }^{8}$ NASA Johnson Space Center, Houston, TX USA \\ ${ }^{9}$ Space and Naval Warfare Systems Center, San Diego, CA \\ ${ }^{10}$ TRACLabs, Inc., Houston, TX
}

\begin{abstract}
We are studying how "robotic follow-up" can improve future planetary exploration. Robotic follow-up, which we define as augmenting human field work with subsequent robot activity, is a field exploration technique designed to increase human productivity and science return. To better understand the benefits, requirements, limitations and risks associated with this technique, we are conducting analog field tests with human and robot teams at the Haughton Crater impact structure on Devon Island, Canada. In this paper, we discuss the motivation for robotic follow-up, describe the scientific context and system design for our work, and present results and lessons learned from field testing.
\end{abstract}

\section{Introduction}

O $\mathrm{NE}$ of the central challenges for space exploration is to develop effective techniques for scientific field work on planetary surfaces. ${ }^{1,2}$ Regardless of the destination (the Moon, Mars, etc.), future investigations will require field work that cannot be fully performed through human extra-vehicular activity (EVA) alone. Similarly, as experience with the Mars Exploration Rovers (MER) has shown, fully satisfying scientific objectives will require more than can be achieved through purely robotic work.

To address this need, we have begun examining how robots can be used for follow-up work. Robots can perform follow-up work that is tedious or unproductive for humans to do. Robotic follow-up might involve: completing geology observations (documenting areas of secondary priority); making highly-repetitive or longduration geologic measurements of a target site or feature (e.g., transect survey); curating samples in-situ; and performing unskilled, labor-intensive work (digging, moving materials and instruments, etc).

\section{A. Motivation}

In most field geology studies on Earth, explorers often find themselves left with a set of observations they would have liked to make, or samples they would have liked to have collected, if only they had been able to stay longer in the field. For planetary field geology, we can imagine mobile robots - perhaps teleoperated 
vehicles previously used for manned exploration or dedicated planetary rovers - being deployed to perform such follow-up activities. ${ }^{2}$ There are several key motivations for taking this approach.

First, had mobile robots been a part of Apollo, they would have enabled additional, valuable observations to be made at key sites. For example, study of the orange pyroclastic glass locality at Shorty Crater (Apollo 17) would have benefited from a transect survey to characterize spatial distribution. Moreover, robotic follow-up would have enabled additional search for green pyroclastic glass near Hadley Rille (Apollo 15).

Looking to the future, it is clear that robotic rovers will be needed on the Moon to achieve scientific exploration objectives. Both the National Research Council and the NASA Advisory Council (NAC) identify key roles for robots. ${ }^{3,4}$ The NAC report states that "to achieve the highest-ranked lunar science objectives, continued robotic sortie missions will be needed, before and after human presence is established".

Moreover, as a stepping stone to other destinations, it is reasonable to assume that humans themselves will be on the Moon. Because humans are able to explore the Moon in-situ, robotic rovers do not need to be conceived as primary (or sole) science instruments. Instead, robots may be designed to perform rote, tedious, or long-duration follow-up tasks and enable humans to focus on activities that require human intelligence, skills and decision-making.

Finally, until a permanently manned outpost is established on the Moon, substantial time will available for robotic follow-up work. If the current "Global Exploration Strategy" is implemented, there will be substantial time and opportunity to use robots to perform work. ${ }^{5}$ Robotic rovers could be put to good use during the time between crews to finish a variety of field work tasks and to prepare for future crews.

\section{B. Key Questions}

In prior work, ${ }^{1,6-9}$ we identified significant differences between how robots have previously been used for exploration and what is needed for future human exploration of the Moon and Mars. For example, past robot explorers (e.g., the Mars Exploration Rovers) were used exclusively as "primary science instruments" operating by themselves, and not as tools to support human explorers.

Thus, if we wish to use robotic follow-up as part of a coordinated human-robot exploration campaign, we need to understand the benefits, requirements, limitations and risks associated with this technique. While the notion of operating robots to complete work started by humans is conceptually simple, many questions must be resolved in order to establish a practical concept of operations.

In brief, the key issues associated with robotic follow-up can be categorized in three areas: (1) robotic rover capabilities; (2) Earth-based ground control; and (3) coordination between humans and robots. Some key questions to be addressed are summarized below:

Robotic rover: How do we adapt follow-up work to specific site, science and tasks? What scientific work can most effectively be performed by robots after human explorers?

Ground control: What ground control structure is needed to support the full range of robotic follow-up activities? How much time and resources does planning and executing robotic follow-up require?

Human-robot exploration: How should robotic follow-up be incorporated into mission planning? How can we optimize human productivity, given what robots can accomplish following human activity?

\section{Concept of Operations}

In our work, we assume the following exploration scenario. Well in advance of a human mission, a science team will plan a traverse involving the use of a crew rover, such as the Lunar Electric Rover. ${ }^{10}$ The science team will use any available a priori data of the traverse area, including orbital remote sensing. During the human mission, astronauts will execute the traverse, identifying sites and tasks for robotic follow-up. After the human mission, the science team will use the data collected, the observations made, and the knowledge gained by the crew to develop a robotic mission. Finally, the robotic mission will be executed in order to perform the follow-up work.

\section{Science Objectives}

To ground our research in an appropriate scientific context, we have chosen to conduct field work at the Haughton impact structure (Haughton Crater) on Devon Island, Canada. This field work focuses on two themes: (1) geologic mapping of the major lithologic units at Haughton Crater; and (2) geophysical survey of the near-subsurface at Haughton Crater. 


\section{A. Haughton Crater}

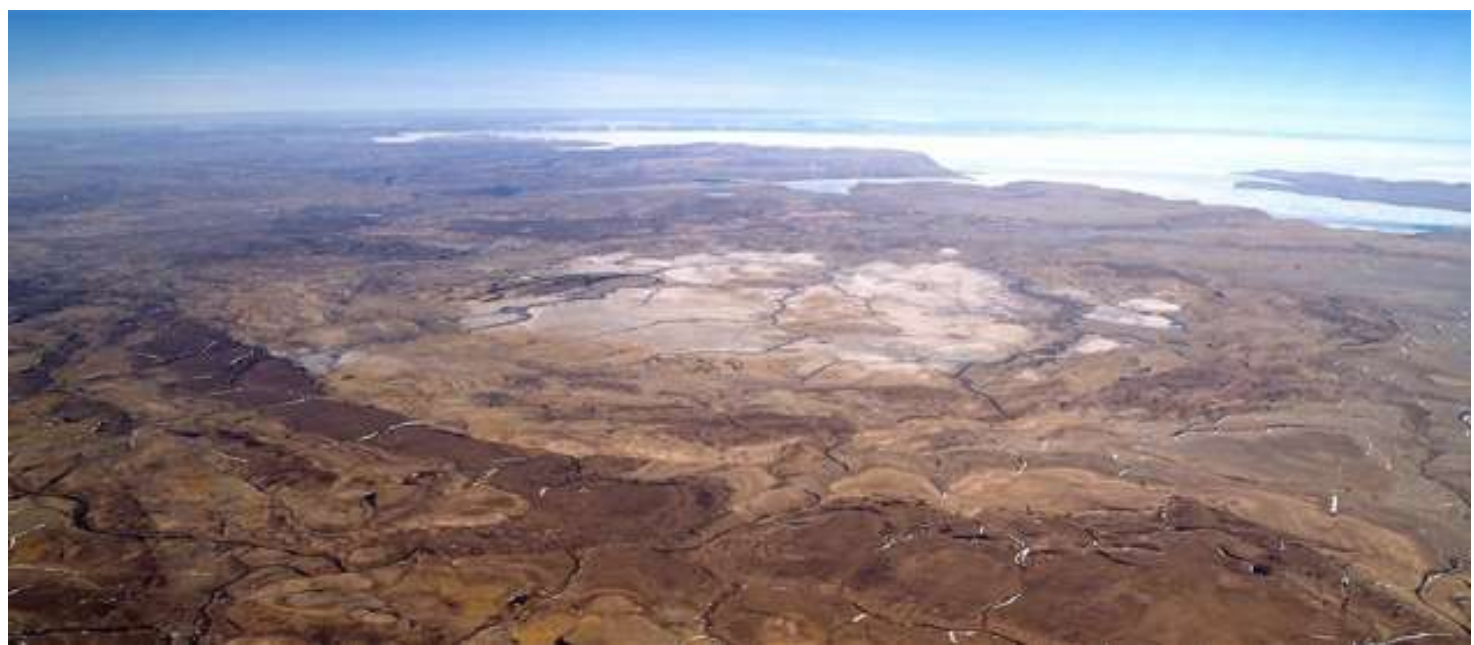

Figure 1. Aerial view of the Haughton impact structure (Devon Island, Canada).

While no single site on Earth is a perfect analog for the Moon, the Haughton impact structure on Devon Island (Figure 1) is a high-fidelity lunar analog in many respects. The crater is $20 \mathrm{~km}$ in diameter and was formed 23 million years ago. It is one of the highest-latitude terrestrial impact craters known on land $\left(75^{\circ} 22^{\prime} \mathrm{N}, 89^{\circ} 41^{\prime} \mathrm{W}\right)$. Haughton Crater lies in the "frost rubble zone" of the Earth (i.e., in a polar desert environment).

We selected Haughton Crater for our proposed field tests based on the lunar science relevance listed in Table 1 and the lunar operations relevance listed in Table 2. In addition, the existing Haughton-Mars Project research infrastructure at the site and our past experience operating at Haughton were important factors in the selection.

Table 1. Lunar science relevance of Haughton Crater

\begin{tabular}{ll}
\hline \hline Impact crater & Impact structures are a fundamental and common geologic lunar feature. \\
\hline Shackleton sized & $\begin{array}{l}\text { Haughton is similar in diameter }(20 \mathrm{~km}) \text { to Shackleton Crater }(19 \mathrm{~km}) \text { near the } \\
\text { lunar south pole. Thus, science issues and investigations about Haughton are at } \\
\text { spatial scales relevant to Shackleton. }\end{array}$ \\
\hline Range of features & $\begin{array}{l}\text { Haughton presents massive exposures of impact-generated materials (e.g., impact } \\
\text { melt breccia), a wide range of impact features (e.g., ejecta blocks), and meter to } \\
\text { multi-km scale impact-produced land forms and structures. }\end{array}$ \\
\hline Impact breccia & $\begin{array}{l}\text { The impact breccia deposits at Haughton represent a single impact event- } \\
\text { generated regolith. These impact breccia present petrologic and mineralogic fea- } \\
\text { tures found only in impact-generated regolith, e.g., shock-fused angular clasts. }\end{array}$ \\
\hline Shocked basement & $\begin{array}{l}\text { Target and country rocks at Haughton present a wide compositional and textural } \\
\text { variety (carbonates, granites and gneisses). The abundance and distribution of } \\
\text { shocked basement rocks provides relevant clues to how crustal materials on the } \\
\text { Moon might have been exposed by impacts. }\end{array}$ \\
\hline Subsurface ice & $\begin{array}{l}\text { Haughton's subsurface is a permafrost rich in ground ice, which occupies much of } \\
\text { the interstitial and pore spaces in the polymict impact breccia. As such, Haughton } \\
\text { offers an interesting opportunity to investigate relationships between subsurface } \\
\text { volatiles and impact generated host substrates. }\end{array}$ \\
\hline \hline
\end{tabular}




\begin{tabular}{ll}
\hline \hline No vegetation & $\begin{array}{l}\text { Because Haughton is set in a polar desert, the landscape at the site is devoid of } \\
\text { vegetation. As such, robotic operations can address many of the issues that will } \\
\text { be encountered on the Moon, including scale, navigation, etc. }\end{array}$ \\
\hline Terrain & $\begin{array}{l}\text { The terrain at Haughton presents a wide range of roughness, slope, and obsta- } \\
\text { cles, which are directly relevant to lunar operations. Steep-walled sinuous valleys } \\
\text { dissecting plateau high grounds around Haughton Crater have a very different } \\
\text { origin from rilles on the Moon, but from an operational standpoint, they provide } \\
\text { adequately relevant obstacles. }\end{array}$ \\
\hline Permanent daylight & $\begin{array}{l}\text { There is permanent daylight in the summer at Haughton, which is critical for } \\
\text { enabling relevant simulations of robotic rover operations on the Moon, both lunar } \\
\text { polar operations and lower-latitude operations. }\end{array}$ \\
\hline Outpost proxy & $\begin{array}{l}\text { The Haughton-Mars Project (HMP) Research Station is established in the rim } \\
\text { area of Haughton Crater (much like a lunar outpost at Shackleton Crater on the } \\
\text { Moon would be) and represents the only infrastructure within an area of several } \\
\text { thousand km }{ }^{2} \text {. Thus, the Research Station can serve as a proxy for a lunar base, } \\
\text { from which our robotic and human vehicular traverses can be deployed. }\end{array}$ \\
\hline \hline
\end{tabular}

\section{B. Geologic Mapping}

The primary objective for geologic mapping is to characterize the composition, distribution, and geologic context of major lithologic units (impact breccia and major types of clasts) exposed at Haughton Crater. This involves discovering and documenting the geologic history of ejecta, the structural geometry (faults, folds, etc.), and sample context. As part of this, sampling of the major units (with emphasis on impact breccia) needs to be performed.

In order to plan mapping traverses (whether human or robotic), numerous factors need to be considered. Some of these factors are easily quantified, but others are not. A field geologist usually has specific goals in mind that are arrived at during preparation of an initial geologic map or study of an existing one.

An important aspect to realize is that field work is most productive when it tests hypotheses. Geologic mapping is not strictly surveying, nor sample and data collection. The task of the field geologist in documenting the geology of an area is to develop an evolving set of multiple working hypotheses and to devise a strategy for testing them through the collection of additional data as exploration of the area continues.

\section{Geophysical Survey}

The primary objective for geophysical survey is to determine the near-subsurface structure of Haughton Crater and the distribution (areal and vertical) of buried ground ice in the permafrost. This survey work serves as an operational analog to investigating near-subsurface volatiles on the Moon. Locating and characterizing volatiles is one of the highest priority lunar science objectives. ${ }^{3}$

To carry out geophysical surveys, we make use of ground-penetrating radar (GPR) to probe the subsurface at different depths and resolutions using radio waves. GPR measures changes in signals induced by geoelectrical properties and structural heterogeneity. As such, it is well suited for detecting ground ice in different substrates, water layering, structural anomalies and fracturing.

While ground ice at Haughton is generally present as continuous permafrost, the depth to the thaw zone base can vary significantly with both location and time. For example, the depth to the permafrost may reach several meters beneath lakes, streams, and channels, rather than the 0.5 to $1 \mathrm{~m}$ that is typical elsewhere. Our GPR surveys at Haughton are intended to identify anomalies in ground ice depth. 


\section{System Design}

\section{A. K10 Planetary Rovers}

In our work, we use two third-generation "K10" planetary rovers (Figure 2). Each K10 has four-wheel drive, all-wheel steering and a passive averaging suspension. The suspension design helps balance wheel/soil forces and reduces the transmission of motion induced by travel over uneven ground. K10 is capable of fully-autonomous operation on moderately rough natural terrain at human walking speeds (up to $90 \mathrm{~cm} / \mathrm{s}$ ).

K10 has mounting points on the front, back, and bottom as well as a $100 \mathrm{~cm}$ high mast. This allows attachment of antennas, sensors, and science instruments. K10's standard sensors include a Novatel differential GPS system, a Honeywell digital compass, Point Grey Research IEEE 1394 stereo cameras, an Xsens inertial measurement unit, a suntracker, and wheel encoders.

K10's avionics design is based on commercial components. The robot is powered by twenty-four (24) hot-swappable Inspired Energy 14.4V, 6.6 AH Li-Ion smart battery packs. K10's controller runs on a Linux-based laptop and communicates via 802.11g wireless, or a Tropos mesh wireless. ${ }^{11}$

The K10 controller is based on our ServiceOriented Robotic Architecture (SORA). ${ }^{12}$ Major

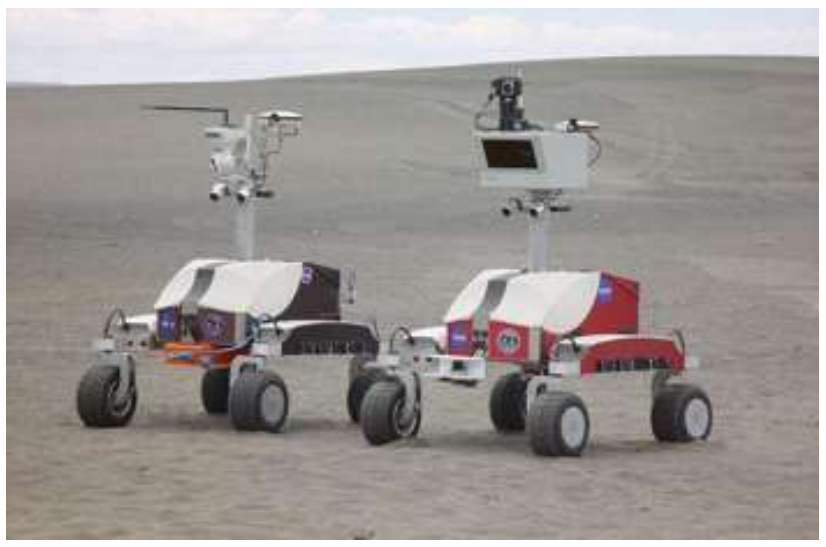

Figure 2. K10 "Black" and "Red" planetary rovers are equipped with a variety of science instruments. services include locomotion, localization, navigation, and instrument control. SORA uses high-performance middleware to connect services. Dependencies between services are resolved at service start. This approach allows us to group services into dynamic libraries that can be loaded and configured at run-time.

\section{B. Science Instruments}

To perform field work, we have equipped the K10 rovers with a suite of science instruments: panoramic and microscopic imagers, a 3D scanning lidar, a ground-penetrating radar and an XRF spectrometer. We selected these instruments based on their capability to inform both geologic mapping and geophysical survey, as well as their suitability for measuring the surface and subsurface characteristics at Haughton Crater.

\section{Imagers}

The K10 rovers are equipped with two science imagers (Figure 3): a custom panoramic imager "PanCam") and a microscopic imager ("MI"). Both the PanCam and MI can provide contextual and targeted high-resolution color imaging of sunlit areas. These instruments are used both for science observations and situational awareness during operations.

The PanCam is a consumer-grade, 12 megapixel, digital camera (Canon PowerShot G9 camera) on a pan-tilt unit. We operate the PanCam at 350 $\mathrm{rad} /$ pixel, which is comparable to the Mars Exploration Rover Pancam (280 rad/pixel). K10's PanCam, however, can be reconfigure for different resolutions by changing zoom. Images are mosaicked in software to create wide-field panoramic views.

The MI uses the same camera model as the Pan-

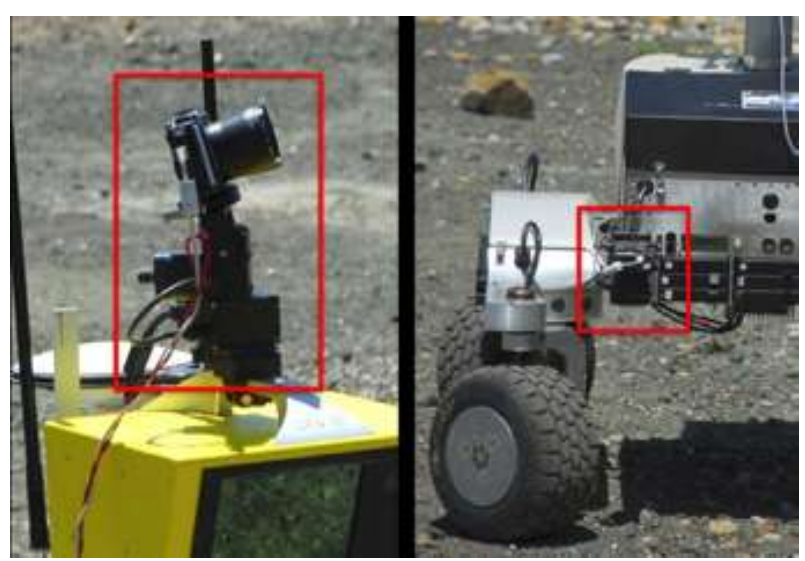

Figure 3. K10's imagers. Left, panoramic imager (PanCam); right: microscopic imager (MI) Cam. However, the MI camera is attached to K10 with a fixed ground (nadir) pointing mount. At highest resolution, the MI provides 33 microns/pixel at the ground, which is comparable to the spatial resolution of the MER Microscopic Imager. 


\section{3D Scanning Lidar}

K10 carries Optech's Intelligent Laser Ranging and Imaging System (ILRIS-3D) on top of central mast (Figure 4), which places the instrument approximately $1 \mathrm{~m}$ above ground. The ILRIS-3D is a scanning lidar designed for terrestrial survey. The instrument provides 3D scans over a 40x40 deg field-of-view and is capable of making measurements from 3 to $1,500 \mathrm{~m}$ range. Typical 3D accuracy is $10 \mathrm{~mm}$ at $100 \mathrm{~m}$ range. Point cloud data are captured at 2,000 points/second, which allows a single, full-resolution scan to be captured in approximately $20 \mathrm{~min}$.

We use this instrument to make 3D measurements of terrain, to examine surface texture (e.g., of outcrops), and to assess terrain hazards (e.g., steep slopes) in sunlit and shadowed areas. During K10 operations, we acquire single scans when the robot is stopped. We also acquire 360 deg panoramas by taking a series of scans with the rover turning in place between scans.

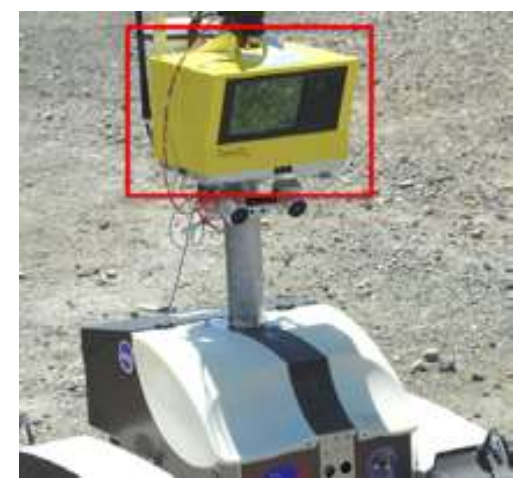

Figure 4. K10 carries a mastmounted 3D scanning lidar.

\section{Ground-Penetrating Radar}

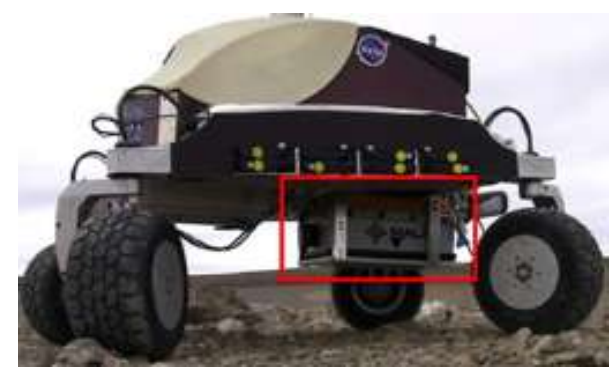

Figure 5. A ground-penetrating radar is mounted underneath K10.
Ground-penetrating radar (GPR) is a non-invasive technique for probing terrestrial and planetary subsurfaces at different depths and resolutions using pulsed radio waves. GPR measures changes in signals induced by geoelectrical properties and structural heterogeneity.

K10 carries the Mala X3M (Figure 5), which is a pulse repetition GPR. We employ a $800 \mathrm{MHz}$ shielded antenna to perform subsurface mapping to $4 \mathrm{~m}$ depth. Although K10 generates electromagnetic noise in the instrument's frequency range, the signature is fairly easy to characterize and can be removed through postprocessing of the radar data.

\section{4. $X R F$}

The Niton XL3T is an x-ray fluorescence (XRF) spectrometer, which is used for non-destructive chemical analysis of rocks, minerals, and sediments. We employ the XRF on K10 (Figure 6) in order to perform real-time bulk analysis of geologic materials. In particular, XRF spectrometry is well-suited for identifying and quantifying (to first order) major elements in rock and soil, as well as for identifying trace elements (with abundances greater than $1 \mathrm{ppm}$ ).

\section{Ground Control Structure}

We remotely operate the K10 rovers using a prototype ground control structure (Figure 7) that we have been developing since 2008. ${ }^{8}$ This ground control structure is intended to support interactive planetary science robotics, such as remote operations on the Moon from Earth ground control. The structure's design draws inspiration from the ground control

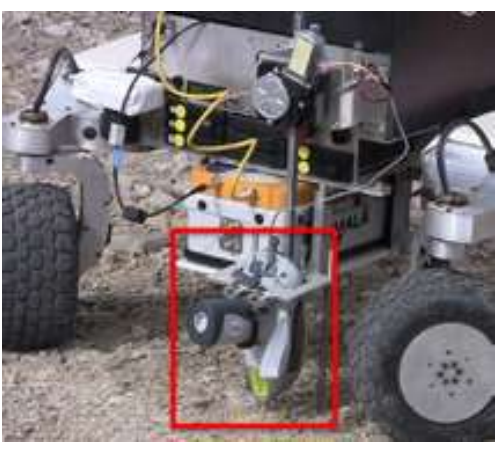

Figure 6. K10 is equipped with a deployable x-ray fluorescence (XRF) spectrometer. used for Apollo, the Space Shuttle, the International Space Station, MER, and the planetary rover field tests that we have conducted during the past several years. ${ }^{1}$

Ground control operations are partitioned into three sub-teams: Flight Control, Science Operations and Robot Support. The Flight Control team is responsible for interactive, tactical decision making and control. The Science Operations team is responsible for planning robot activities (based on science objectives) and for analyzing data acquired by the robot. The Robot Support team responds to robot performance and health issues, as well as provides technical support to the other teams.

The Flight Control Team conducts overall monitoring, commanding and real-time response of the robot and its major subsystems. The team has a hierarchical chain-of-command involving six positions: 


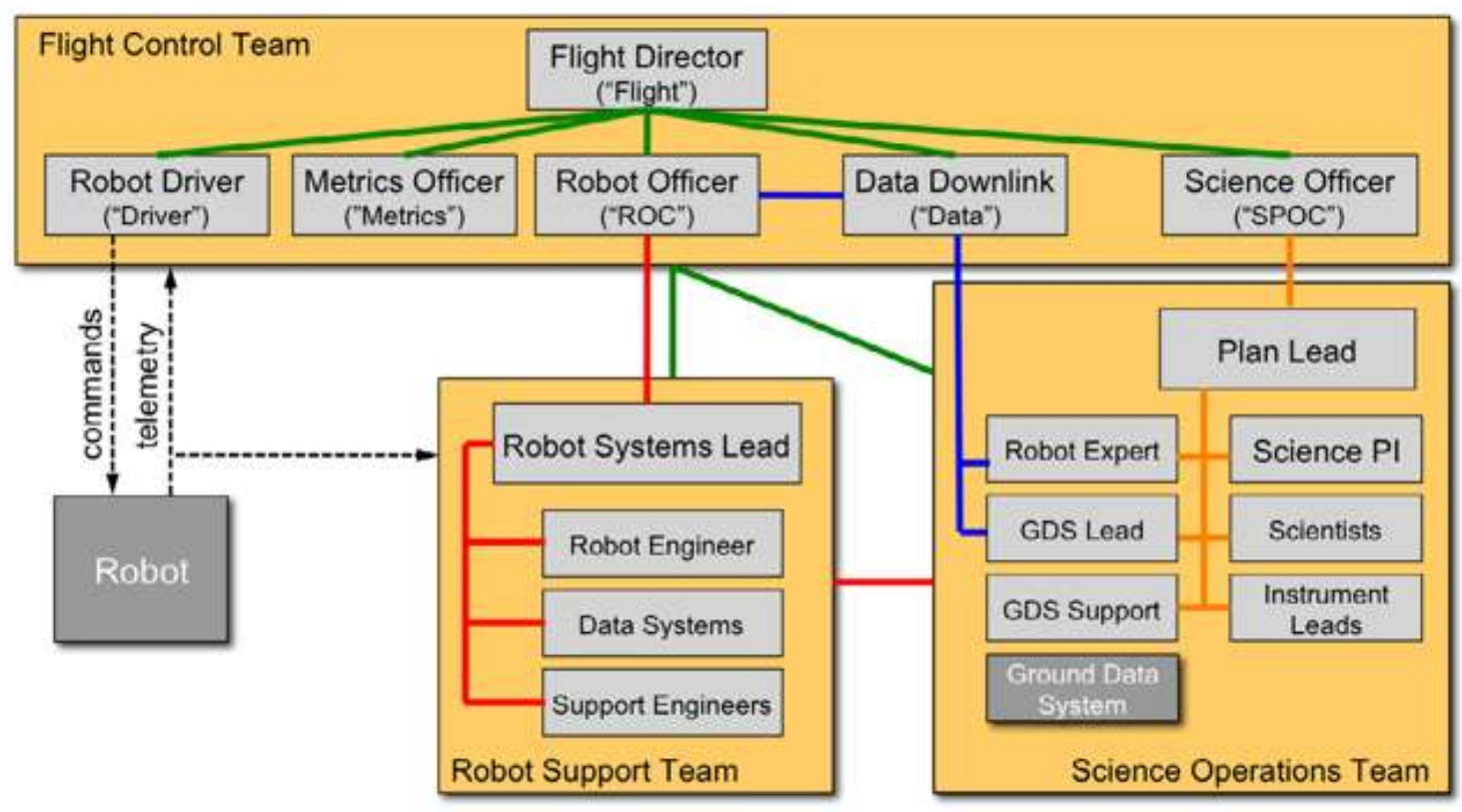

Figure 7. Prototype ground control structure

- Flight Director. "Flight" is the executive in charge of ground control. He coordinates and reviews information from the Flight Control Team and makes decisions to achieve mission objectives.

- Robot Driver. "Driver" is responsible for robot mobility and real-time science ops (e.g., interactively panning cameras to look at specific targets or direction).

- Metrics Officer. "Metrics" monitors robot performance to determine task progress and completion.

- Robot Officer Coordinator. "ROC" monitors and controls all robot subsystems. He reviews and coordinates information from the Robot Support Team to handle contingencies.

- Data Downlink. "Data" manages data communications with the robot, including the communications link and data transfers.

- Science Protocol Officer Coordinator. "SPOC" represents the Science Operations Team. He provides explanation about robot plans, monitors science telemetry, and performs real-time science decision making.

The Science Operations Team functions much like the MER Science Operations Working Group (SOWG). ${ }^{13}$ For interactive planetary science robotics, operations are potentially continuous and low-latency, so our planning cycle is designed to be rapid and iterative throughout the mission. This team is comprised of an overall Science PI supported by participating scientists and instrument experts.

One distinctive position in the Science Operations Team is that of Plan Lead. This person maintains communications with "SPOC" during execution of the current robot plan and coordinates development of the next plan to be executed. When execution and planning is complete, the Plan Lead rotates with SPOC in order to bring the new plan to the Flight Control team. In this manner, the Science Operations Team is able to be responsive and adaptable to contingencies and serendipitous opportunities.

The Robot Support Team provides real-time support to the other teams in different ways. For Flight Control, the team provides expertise on specific robot subsystems (hardware and software) when issues are beyond the ROC's knowledge or ability to analyze or debug a situation. For Science Operations, the team provides advice on robot performance (e.g., where the robot can, and cannot, operate) as well as payload operations (e.g., whether there are any concerns about using a particular instrument).

All of the ground control teams coordinate and communicate through voice loops and instant messaging, which are partitioned according to team. Communication between teams is generally initiated using pointto-point links. Once initiated, however, the conversation can be taken to the appropriate voice loop. For example, an instrument specialist from the Science Operations Team might speak on the Flight Control voice loop to explain unexpected instrument readings. 


\section{Operational Timeline}

Figure 8 illustrates the steps of the operations cycle used by our ground control team. Planning and execution are pipelined and may take place in parallel. At the start of each cycle, the Science Operations Team creates an activity plan for the robot that balances short-term science opportunities with over-all science objectives. The Science Operations Team consults with the Robot Support Team (or a co-located representative) on the feasibility of their goals for robotic execution.

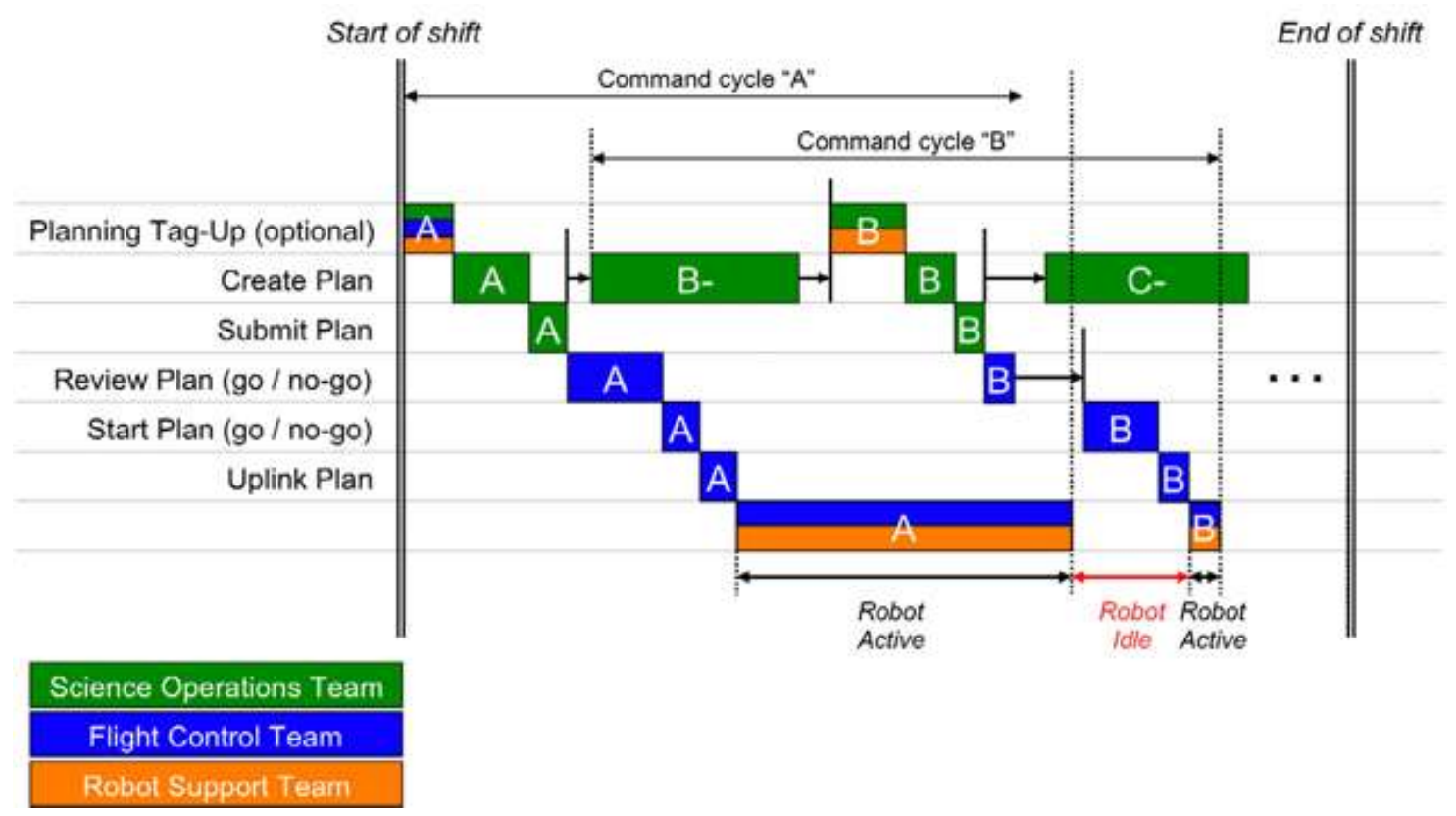

Figure 8. Operational timeline

Next, the activity plan is submitted and briefed to the Flight Control Team for approval, then "uplinked" to the robot for execution. While Flight Control is monitoring and managing the execution of the plan by the robot, the Science Operations Team begins the next planning cycle. The Robot Support Team assists with robotic operations and has a time-slot at the end of the operations cycle to schedule maintenance tasks, or to upload configuration changes to the robot.

This pipelined approach is designed to minimize the time during which the robot has finished executing a plan and the Science Operations Team is still developing the next plan. The time between when the robot completes one plan and begins execution of the next plan is called "robot waiting". We strive to minimize this time, in order to obtain maximum utilization of the robot. However, this is not always achievable. In particular, science data acquired by the robot during execution of a plan often influences the next set of robot activities. Thus, the planning process must take these into account.

\section{E. Ground Data System}

During remote robot operations, the ground control team uses a variety of software to manage the uplink process (from planning to sending commands to the robot) and the downlink process (monitoring telemetry from the robot and processing acquired data).

\section{Uplink}

For the uplink process, we use several tools to remotely operate K10 in different control modes. Our preferred operational mode is supervisory control, in which K10 carries out activity plans in an autonomous manner while ground controllers monitor its progress. Activity plans are simple command sequences that specify waypoints (locations for the robot to drive to) and data collection tasks. In this mode, K10 automatically drives from waypoint to waypoint, continuously navigating around obstacles and terrain hazards.

We use "Google Earth Ops" (GeOps), shown in Figure 9, to create activity plans. GeOps is a lightweight user interface built on top of the Google Earth geo-browser. Activity plans are constructed by selecting robot 


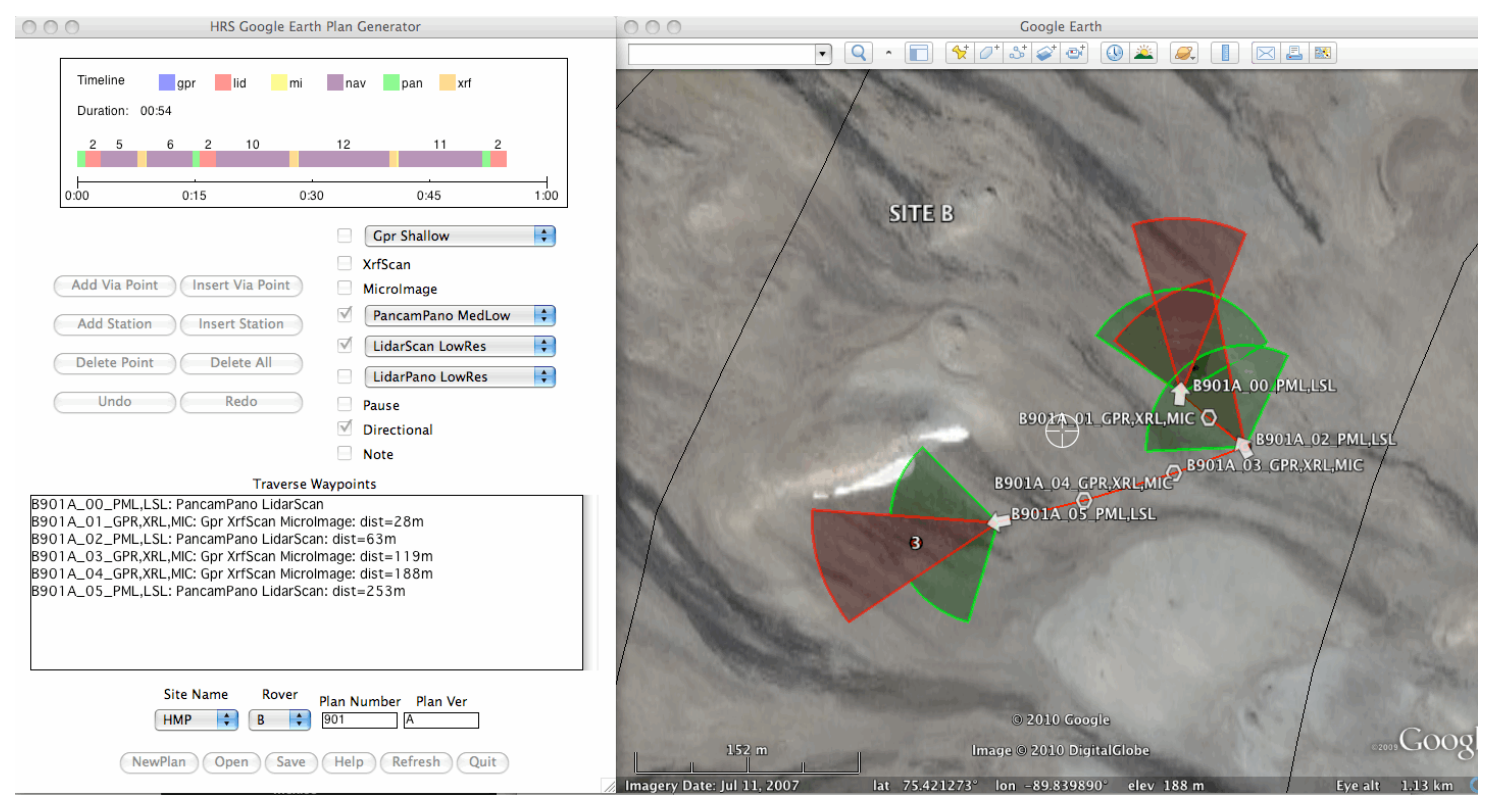

Figure 9. Google Earth Ops. Left, control panel shows the plan timeline and task list; right, Google Earth shows the rover path and directional waypoints with colored wedges (instrument fields of view).

tasks (navigation, instrument operations, etc.) and then designating associated waypoints on the Google Earth map. Waypoints may be directional, which enables the robot to approach a location, or point an instrument, with a specific orientation. GeOps shows the task list as the activity plan is developed, as well as an estimated timeline required for the robot to carry out the plan.

Uplink also includes tools for controlling the robot's subsystems, configuring operational parameters (telemetry message sets, autonomous driving thresholds, etc.) and direct teleoperation (position and rate control). We use these tools primarily to: (1) manually operate the robot in situations where its on-board autonomy performs poorly (e.g., in very cluttered environments); and (2) handle contingencies that require manual intervention.

\section{Downlink}

On the downlink side, we employ numerous tools to monitor rover activity, to download and process science instrument data, to archive and manage data products, and to display and analyze data.

The "Visual Environment for Robotic Virtual Exploration" (VERVE), shown in Figure 10, is an interactive, 3D user interface for visualizing high-fidelity 3D views of rover state, position, and plan status on a terrain map in real-time. VERVE also provides detailed status displays of rover systems, renders 3D data (e.g., range data acquired with 3D scanning lidar), and can monitor robot cameras. VERVE runs within the NASA Ensemble framework ${ }^{14}$ and supports a variety of robot telemetry, including the NASA "Robot Application Programming Interface Delegate" (RAPID) messaging system. ${ }^{15}$

Once science instrument data has been downlinked from K10 and processed into our ground data system, users can use a Web-based science interface (Figure 11) to access the data. This interface features an interactive 3D map (based on the Google Earth plug-in), which displays geo-referenced placemark icons for all the data acquired by K10. To distinguish between data types, different placements are used for each instrument: yellow squares ("M") for MI images, green wedges ("P") for PanCam panoramas, pink wedges ("L") for lidar data, and orange hexagons ("X") for XRF data. Because GPR data is associated with transects (i.e., no single position), no placemark icons are shown. Preview images (which are cross-linked to the placemarks) and search-based filtering enable rapid data access. Users can click on the placemarks or preview images to access the source data.

\section{Rover Performance Assessment}

The objective of rover performance assessment is to determine how well the K10 rover is performing its assigned tasks. This assessment is aided by software that monitors data sent from K10 in real-time and 


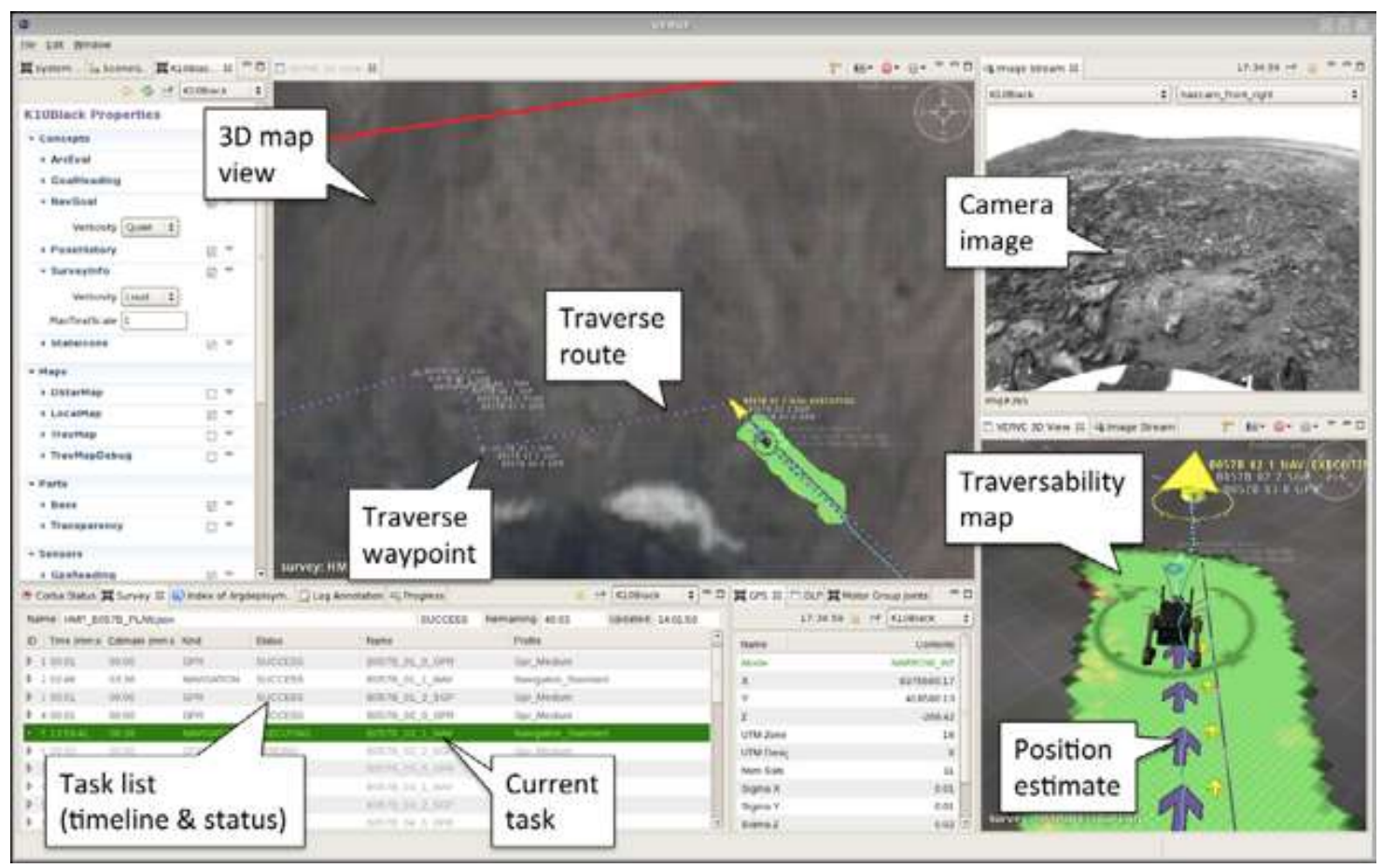

Figure 10. The Visual Environment for Robotic Virtual Exploration" (VERVE) is an interactive 3D user interface for monitoring robot operations.

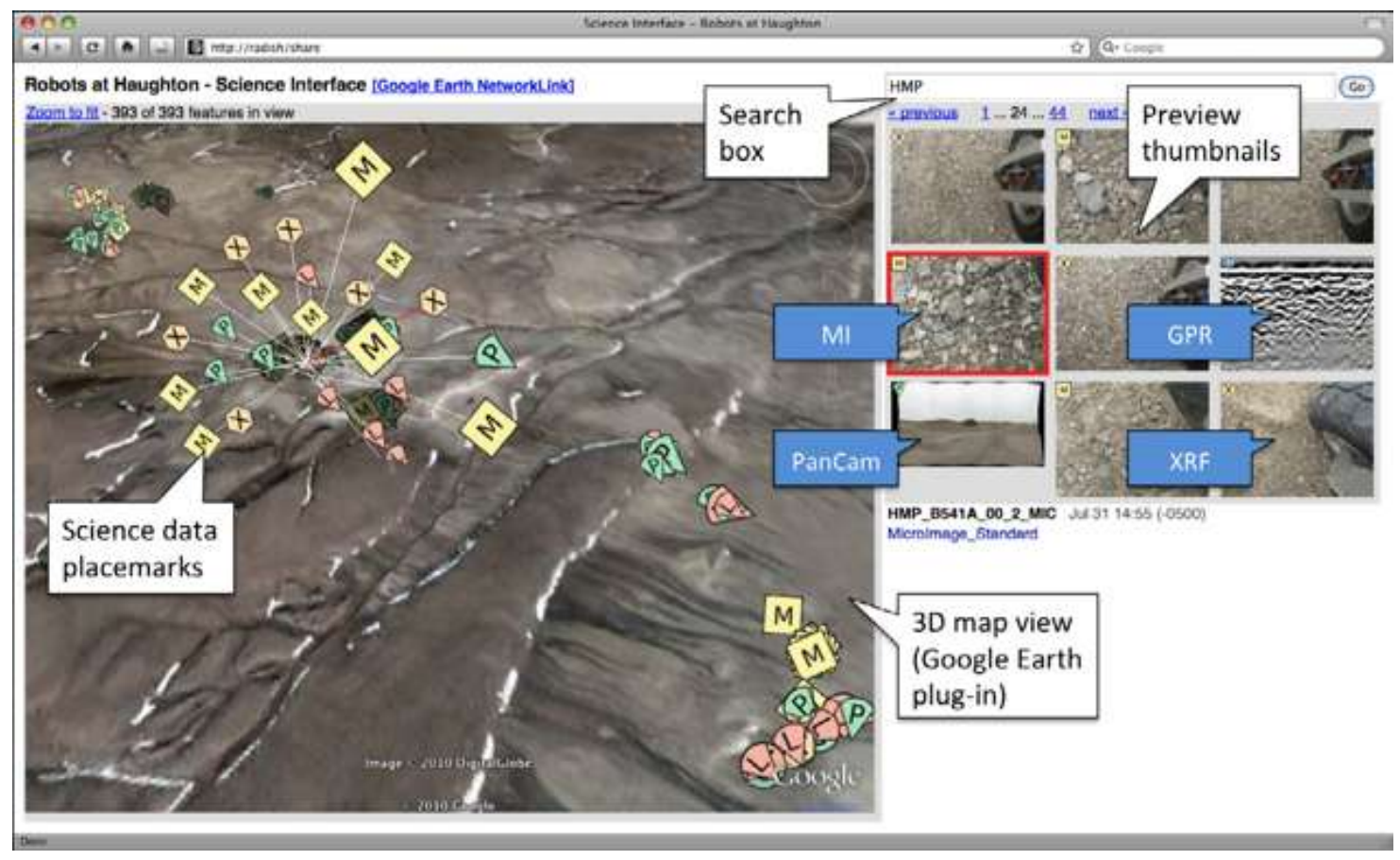

Figure 11. A web-based interface is used to access science data collected by K10.

measures the rover's task performance while it is operating in the field. ${ }^{16,17}$

Many of the performance metrics computed in real-time characterize the rover's progress on assigned tasks (navigating to a waypoint, acquiring data from an instrument, etc.) This information is used by the Flight Director to: (1) determine if adequate time remains to complete a particular task, (2) determine if adequate resources (battery power, communications bandwidth, etc) are available to complete the task (including data transfers), and (3) determine if tasks should be aborted, or skipped, in situations where the 
science plan cannot be completed as intended.

Task progress measures how much longer it will take until a task is complete and whether the task is progressing normally. Task progress can be assessed from two perspectives that correlate to the rover's software architecture. The mission perspective corresponds to the modules that execute the science plans containing the traverse and data collection tasks. The subsystem perspective corresponds to the modules that manage rover locomotion and navigation, and the rover instruments that collect data.

During operations, we use both perspectives to monitor progress. For example, the time spent in task from the mission perspective is computed as the time elapsed between task initiation and task success as assessed by the mission software. The corresponding time in task from the subsystem perspective is computed as the time elapsed between subsystem activation and deactivation as assessed by the subsystem software. When the mission and subsystem task times are in good agreement, the confidence increases that a task will complete normally. Confidence is further improved when these times compare favorably with the average times observed for the particular type of task.

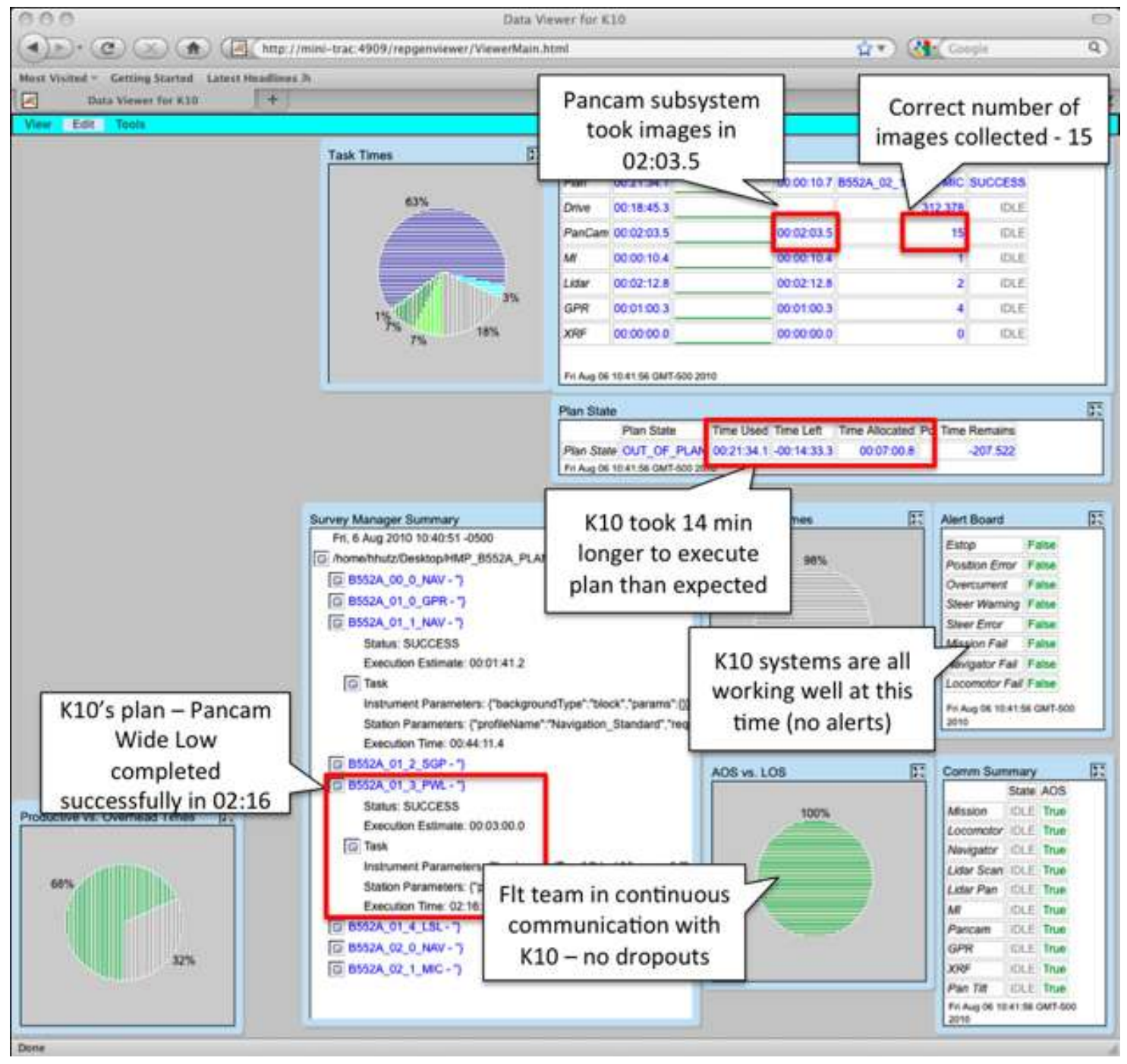

Figure 12. Performance monitoring display

To illustrate how the performance monitoring software assesses task progress, consider an example from August 6 at Haughton Crater. The rover's plan included a task to take wide, low-resolution panoramas. Based on observation of similar imaging tasks, this task was expected to take $02: 15$ and collect 15 images. In Figure 12, we see a display of performance metrics for the plan containing this task. 


\section{Simulated Crew Mission (2009)}

\section{A. Description}

In July 2009, we conducted a simulated lunar crew mission at Haughton Crater. A geologist (M. Helper) and a geophysicist (E. Heggy) planned vehicular traverses using a HMMWV as a simulated pressurized crew rover. Each traverse was performed by a two-man crew and included short extravehicular activity (EVA) conducted on foot with unpressurized concept space suits (Figure 13).

Prior to the mission, we developed a preliminary geologic map of the site using remote sensing data. This data included digital elevation models $(14 \mathrm{~m} /$ post regional and $1 \mathrm{~m} /$ post at Haughton Crater), a panchromatic Quickbird orthophoto $(60 \mathrm{~cm} /$ pixel $)$, black-and-white aerial photos (non-orthometric), panchromatic Landsat Band $8(14 \mathrm{~m} / \mathrm{pixel})$, ASTER $(100 \mathrm{~m} / \mathrm{pixel})$, and aerial radar (approx. $100 \mathrm{~m} /$ pixel).

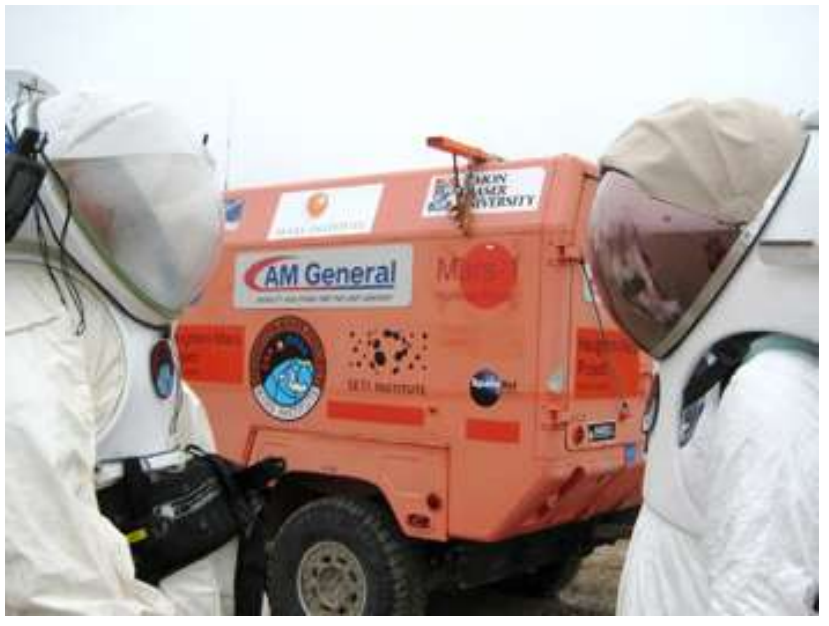

Figure 13. Concept space suits and a HMMWV were used to simulate a lunar crew mission.

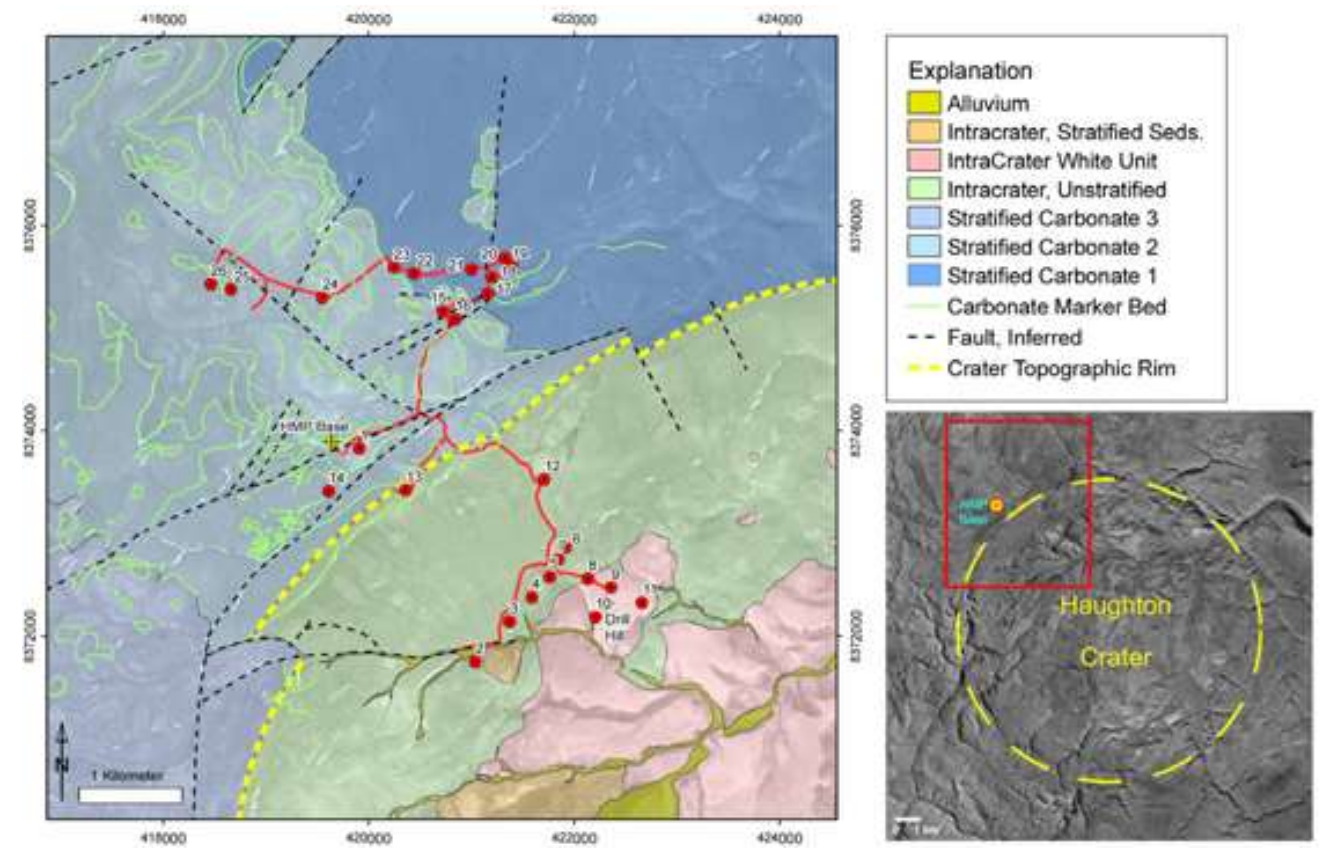

Figure 14. Preliminary geologic map and planned geologic mapping traverse (red).

The geologic mapping traverse was designed primarily to test the preliminary geologic map. In particular, the route was chosen to explore the characteristics of the map units defined by albedo and compositional (i.e., ASTER data) contrasts, as well as structural elements revealed by elevation and slope data. Figure 14 shows the preliminary geologic map and planned geologic mapping traverse.

The geophysical traverse (Figure 15) was planned to observe the patterned ground ("polygons") features near the crater rim in hopes of determining the origin of these features. To probe for ground ice in the subsurface, we equipped the HMMWV with GPR instruments and also manually deployed these GPR during simulated EVA stops along the traverse (Figure 16). We also planned to acquired 3D lidar scans and images to determine surface roughness characteristics, grain sizes, and compositions of surface materials.

The data collected by the geophysical traverse was intended to test two hypotheses of how polygon features originated. The first hypothesis is that cracks result from thermal contraction of the ground and gradually fill with ice over time. Vertical wedges of ice cause the polygonal shape at the surface. Additionally, 


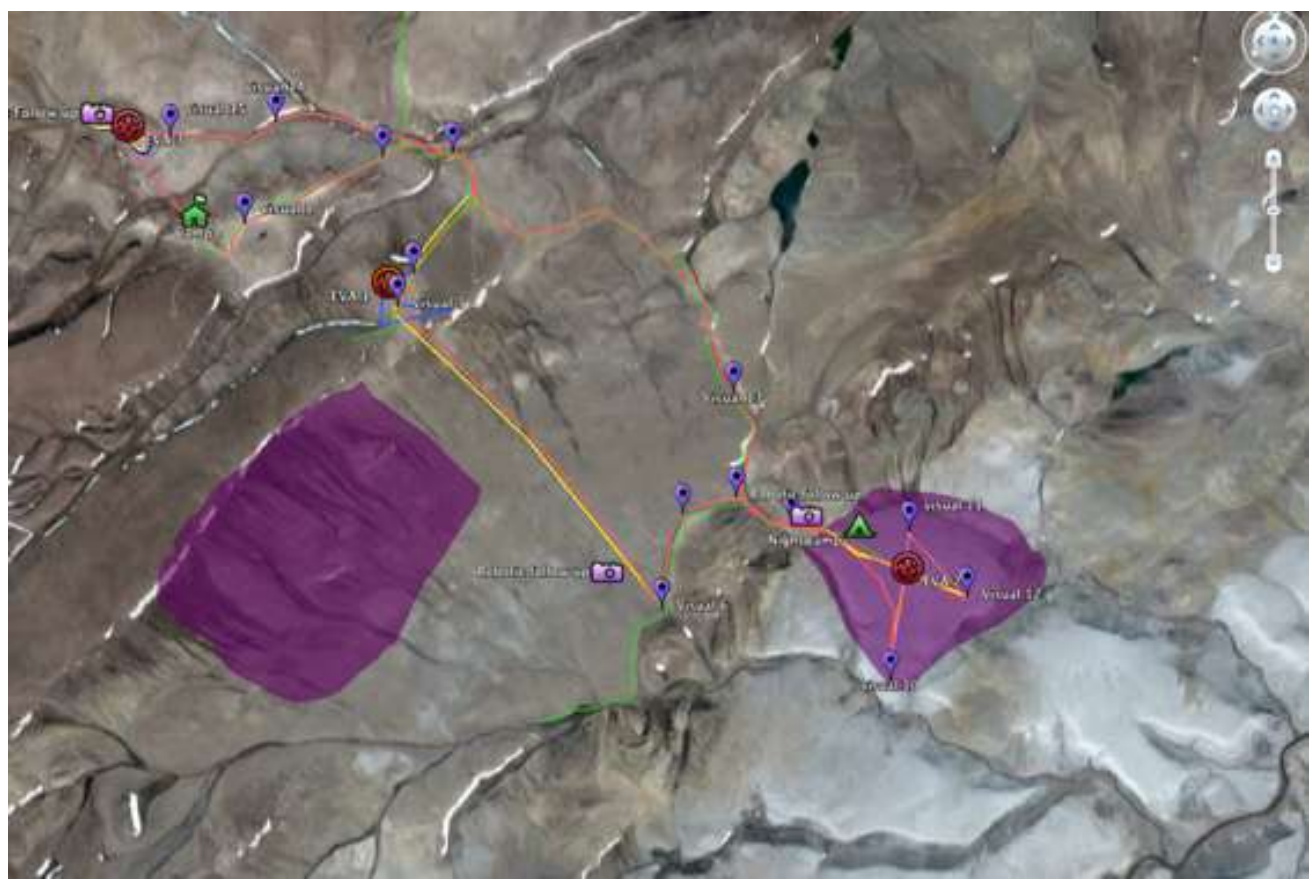

Figure 15. Planned geophysical traverse with manually deployed GPR transects.
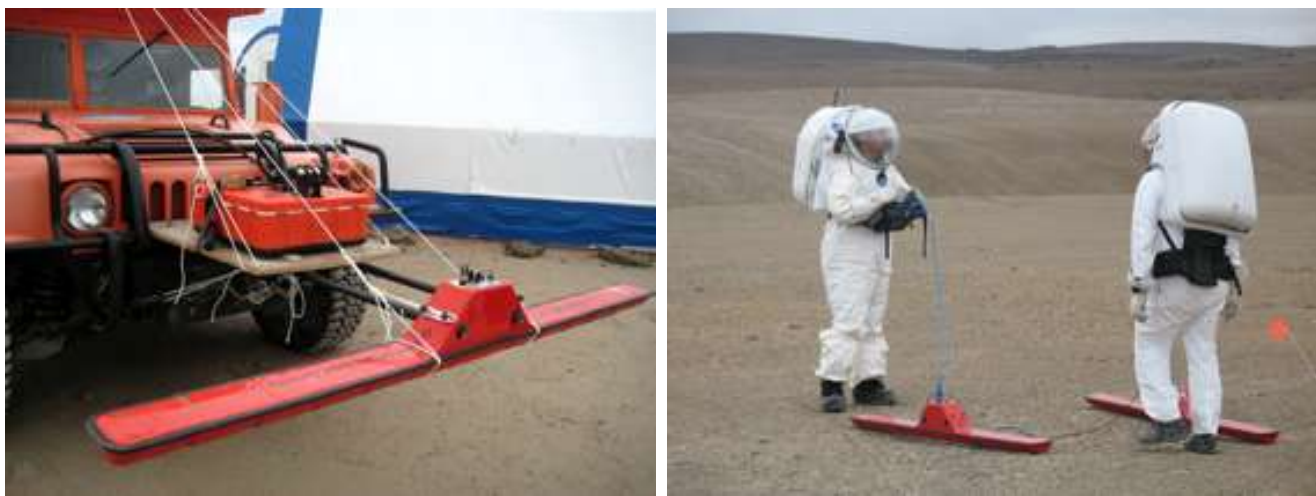

Figure 16. Ground-penetrating radar (GPR) at Haughton Crater. Left, a GPR is mounted on the front of a simulated pressurized crew rover; right, GPR is manually deployed by suited crew.

Table 3. Flight rules for simulated crew mission

\begin{tabular}{ll}
\hline \hline Ranging & - Maintain line-of-sight to vehicle or other crew \\
constraints & - Max. EVA walking range: $200 \mathrm{~m}$ \\
& - Avg. driving: $4 \mathrm{~km} / \mathrm{hr}$ \\
& - Max. driving: $12 \mathrm{~km} / \mathrm{hr}$ \\
\hline Time & - Max. traverse time: $10 \mathrm{hr}$ \\
constraints & - Avg. EVA time: $3.5 \mathrm{hr}$ \\
\hline Sampling & - Vehicle: robotic arm \\
& - EVA: manual \\
\hline \hline
\end{tabular}

surface cracks should be filled over time by alluvium, so that the polygonal shapes are seamless. The second hypothesis is that polygons form by overlying bodies of ice, which lead to desiccation. As water evaporates 
over the ground, contraction and expansion occurs seasonally. In contrast to the subsurface ice hypothesis, cracks should be unfilled and sharp.

To more closely simulate a future lunar mission, we constrained all traverse plans to follow a set of flight rules (Table 3), which reflect recent lunar exploration architectures developed by NASA.

\section{B. Data from Crew Traverses}

\section{Geologic Mapping}

On the geologic traverse, M. Helper took 155 photographs (Figure 17) and collected 19 hand specimens (Figure 18) of impact breccia, basement clasts, carbonate fault breccia, fossil-bearing dolostone, dolostone from several parts of the carbonate section, and soil samples from crater fill units.
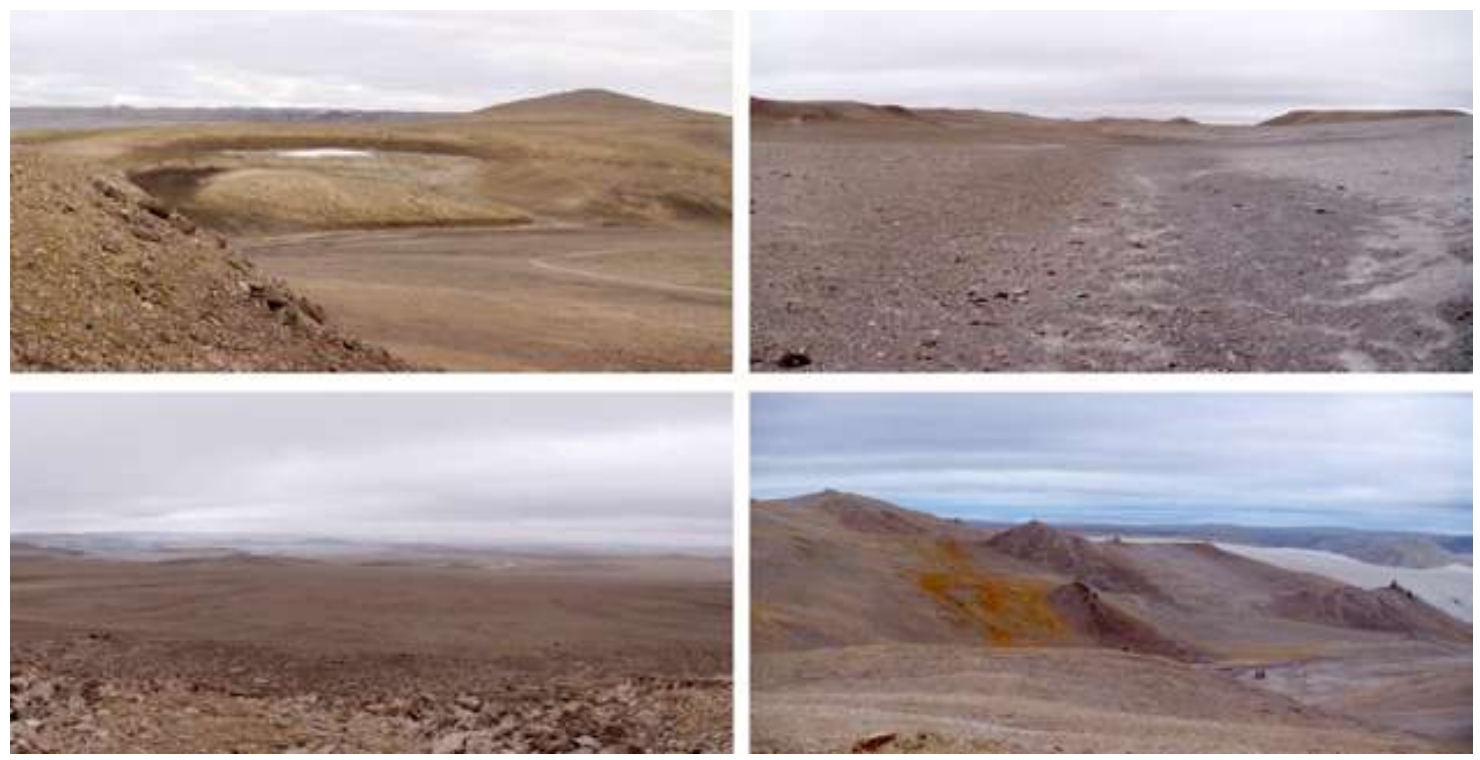

Figure 17. Four of the panoramas taken during the geologic mapping traverse. Top left: the rounded, brown, low relief terrain in the middle ground are the intra-crater stratified sediments; top-right: Contact between gray carbonate breccia (right) with unstratified intra-crater carbonate; bottom-left: view East into the crater from the rim near station 13; bottom-right: intra-crater gray carbonate breccia forms the distinctive white ridge in right middle of photo.
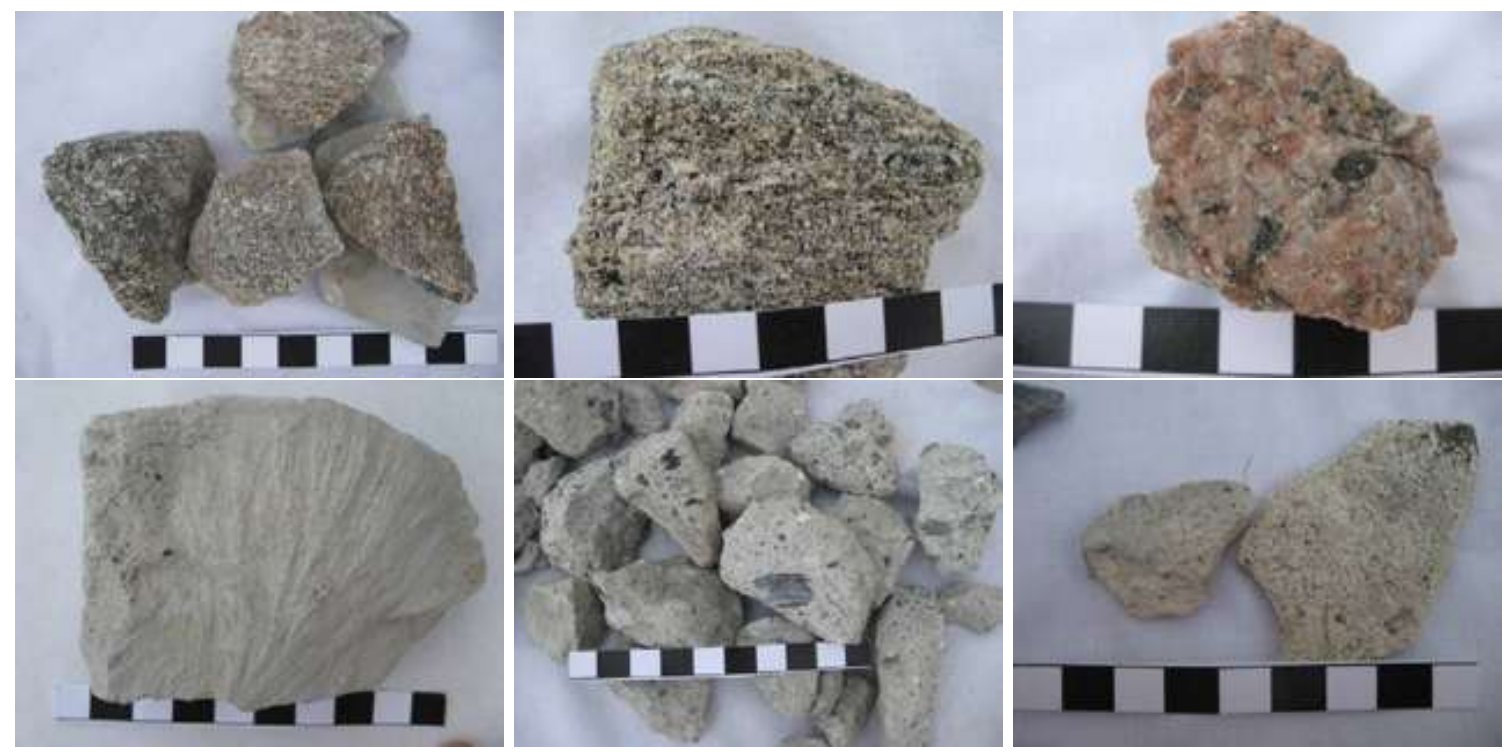

Figure 18. Impact derived samples collected during the geologic mapping traverse. Top row: shock metamorphosed basement clasts; bottom row: shatter cone in limestone clast, polymict gray breccia, "vesicular" carbonate. 


\section{Geophysical Survey}

On the geophysical traverse, E. Heggy obtained 3D Lidar scans of gullies on the crater rim (Figure 19), and $400 \mathrm{MHz}$ and $900 \mathrm{MHz}$ GPR traces along the crater rim. Figure 20 shows two representative GPR traces, which indicate the bottom of the active layer at approximately $2 \mathrm{~m}$ beneath the surface.

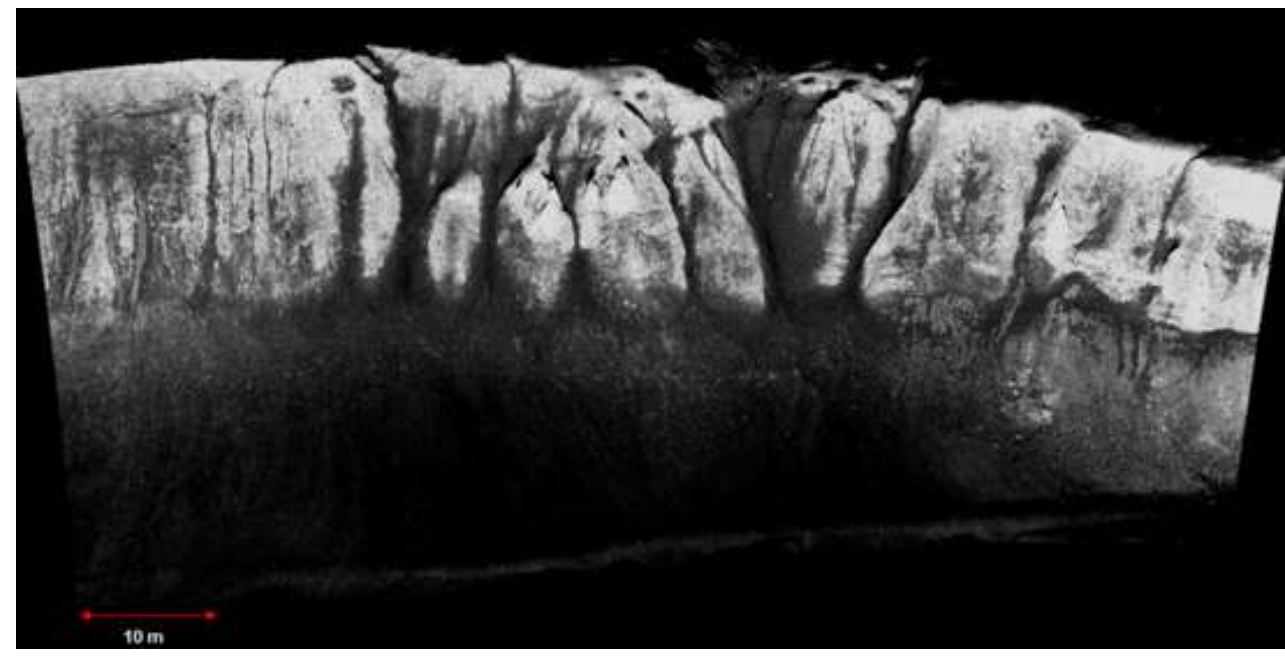

Figure 19. 3D scanning lidar image of gullies on the Haughton Crater wall.
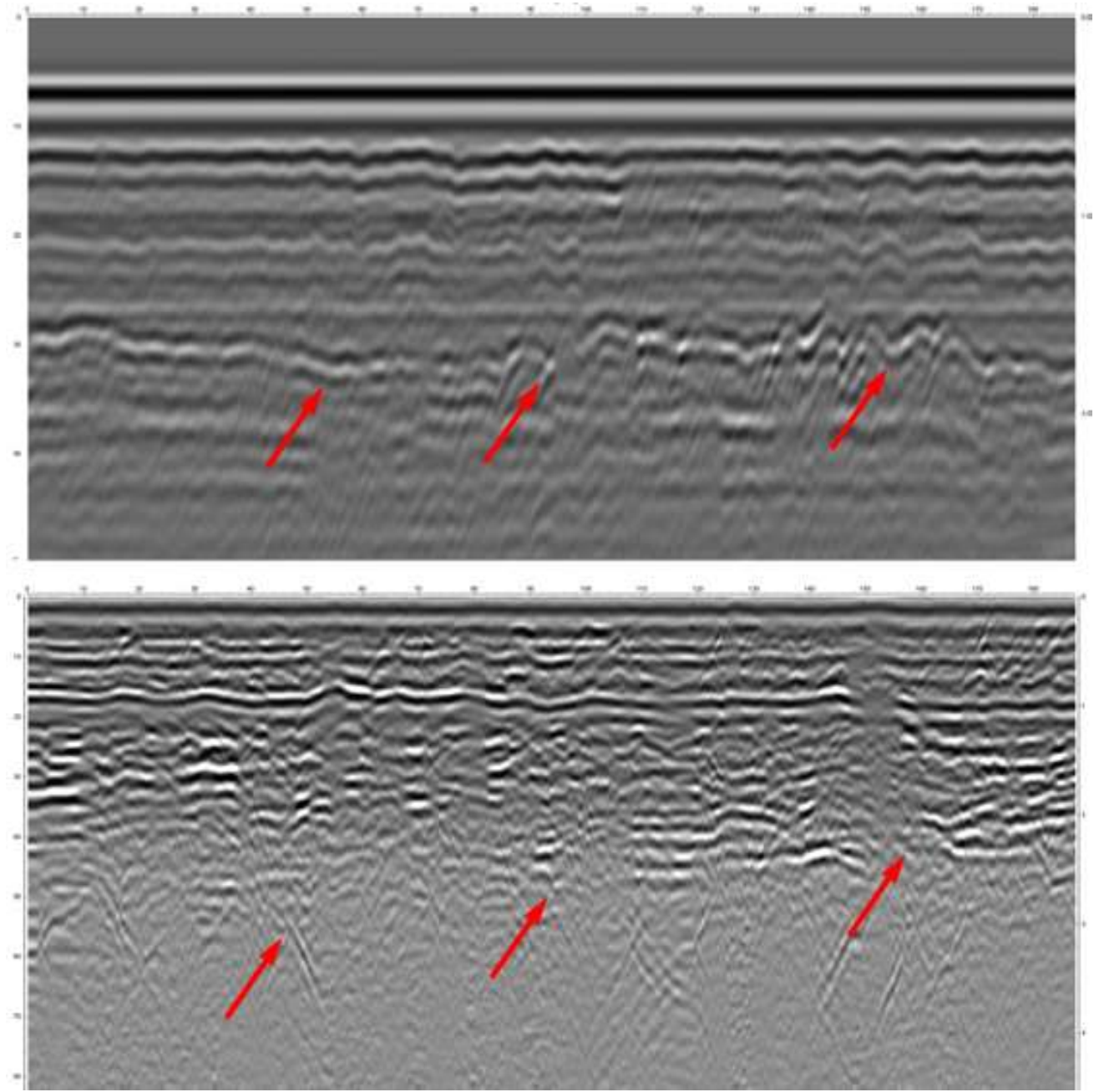

Figure 20. GPR traces showing subsurface ice wedges (red) at different locations. Top: $400 \mathrm{MHz}$ measurements; bottom: $900 \mathrm{MHz}$ measurements. 


\section{Robotic Follow-up Planning}

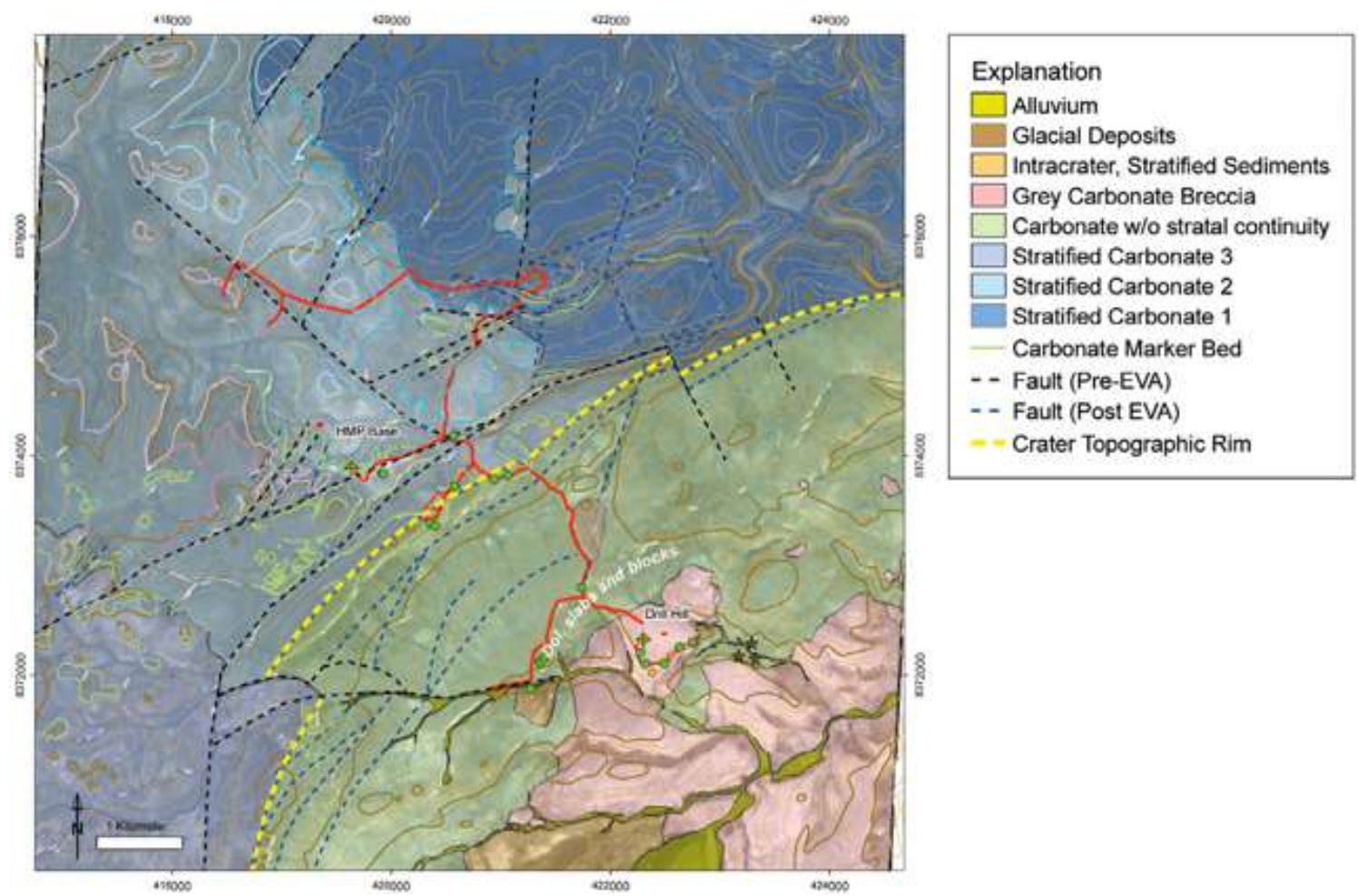

Figure 21. Revised geologic map. Green dots are sample localities. Blue dashed lines indicate new faults added to the original map.

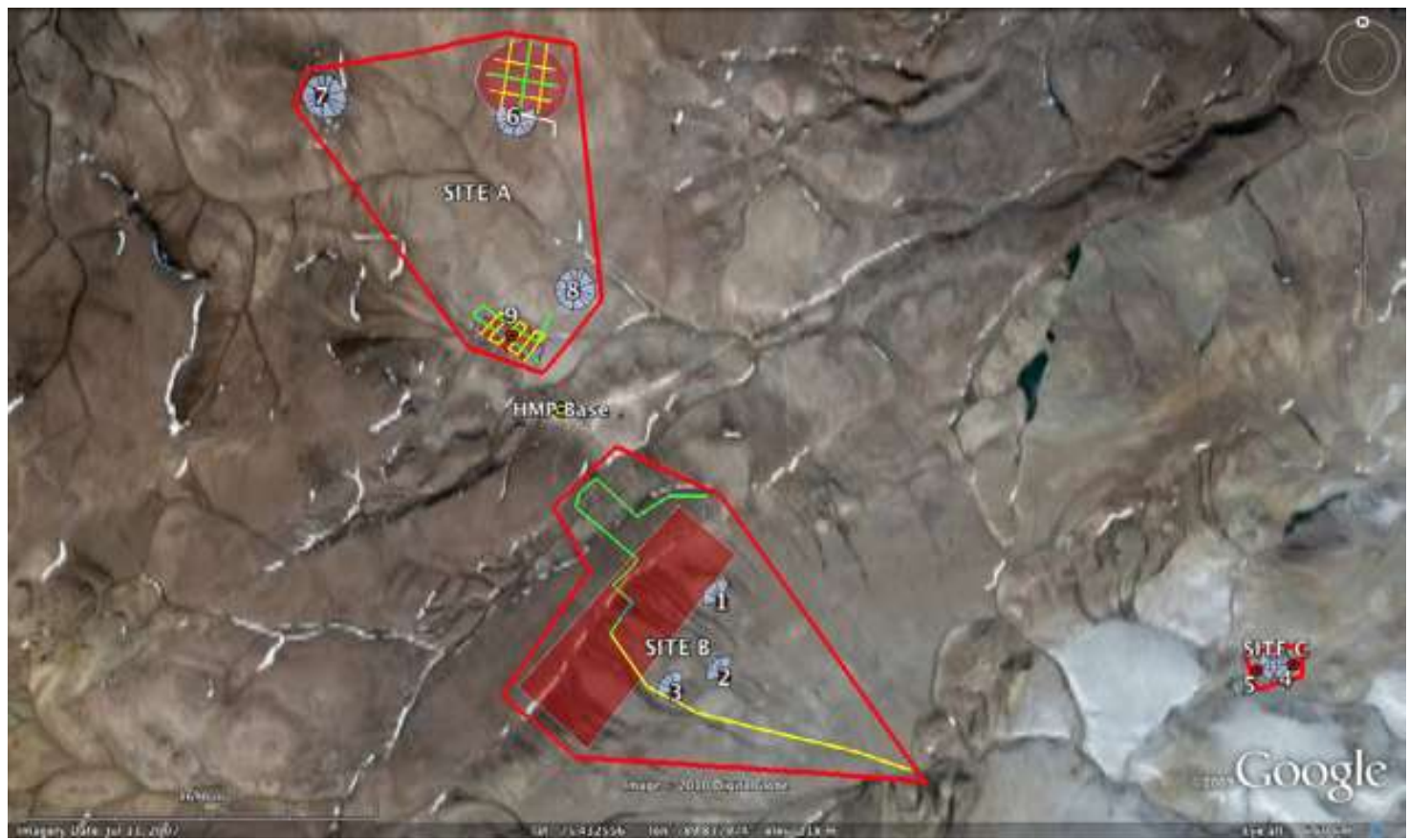

Figure 22. Robotic follow-up locations. Yellow and green lines indicate GPR traverses, blue wedges indicate camera fields-of-view. Lidar scans and pancams associated with GPR traverses are omitted for viewability.

Following the conclusion of the simulated crew mission, we revised the geologic map (Figure 21) to incorporate data from the crew traverses. Note the difference in the unit names on this map compared to pre-traverse map (Figure 14). Next, using this revised map, we began planning the robotic follow-up mission. 
To start, we identified locations for additional field work. A site is a region that contains multiple science targets within a logistically compact area. A locale is a focused region of operation for the robot with specific science activities to be performed. We selected sites based on their importance to furthering the geologic mapping and geophysical survey studies. Figure 22 shows the three sites and nine locales selected for robotic follow-up.

Next, we prioritized the sites and the locales within each site to create a hierarchy of investigations. We then developed initial robot traverse plans, including data acquisition activities and time estimates for each traverse. Finally, we incorporated other mission constraints (logistics, communications coverage, and schedule margin) to create an overall campaign strategy and schedule.

\section{Geologic Mapping}

Site A was identified as the highest priority for robotic follow-up for geologic mapping. At Locales 6, 7, and 8, we planned to use PanCam and Lidar to obtain oblique views of the carbonate stratigraphy outside of the crater. This was expected to help better constrain the location and orientation of faults.

Site $\mathrm{C}$ was given second priority for geologic mapping. The objective at Locales 4 and 5 was to discover the nature and local extent of the "red soils", an orange-red hued superficial staining on apparent carbonate blocks and clasts that may comprise the crater floor beneath the white impact melt breccias. We planned to acquire MI, PanCam, Lidar and XRF data from these locales in order to examine the "soils" in detail, to map the distribution of the staining, to look for constructional features (e.g. travertine deposits), and to assess the nature of the lithology (ies) at the site. XRF analysis was expected to help determine the composition of the red coatings.

Site B was considered as lowest priority. At Locales 1, 2, and 3, the central objective was to examine large blocks that rest on west slope of the crater wall. PanCam and Lidar data was to be used to test the hypothesis that these are either layered dolostone blocks (down-faulted from the topographic rim) or impact ejecta blocks/breccias. If the former, the expectation was that layering should be present and perhaps inclined with at least some westward component into the slope. If the latter, breccias textures and/or highly disrupted bedding should be evident, with layering (if present) perhaps inclined in such a way that it bears no relationship to the layering at the topographic rim.

\section{Geophysical Survey}

Site B was identified as the highest priority for robotic follow-up for geophysical survey. At locales 1, 2, and 3 , the central objective was to explore the presence, state, horizontal distribution and depth of the subsurface ice (permafrost). PanCam images were expected to provide the geological context of the gullies, exposed ice, soil moisture and rock oxidation level. Lidar data was to provide textural information on surface roughness, fracture distribution and the depth of the gullies.

To understand the depth of the active layer (i.e. the upper interface of the permafrost), both the GPR and orbital SAR images were to be used. XRF and MI were to be used to assess the composition of the soil and oxidized mineral, in order to validate the water ice origin. Results from the PanCam, Lidar were to be correlated with the GPR and ALOS L-Band SAR images in order to examine distribution of the permafrost depth and define optimal locations for shallow drilling.

Site A was given second priority. At Locales 6 and 9, the objective was to explore the origin of the polygons and their association to the permafrost thermal instability and potential melting dynamic. PanCam and Lidar data were to provide detailed geomorphological characterization of the polygons to be probed. GPR data was intended to be used to assess fracture orientation and the depth of the permafrost forming them. Finally, MI data was to be used to study the fractures forming the polygons and the XRF was to be used to assess hydrated minerals, which would confirm the water origin of the ice.

In addition to the geological and geophysical knowledge gained from characterizing volatiles on planetary surfaces and their role in planetary surface evolution, the characterization of these two geomorphological features was intended to serve as a valuable exercise for locating sustainable in-situ resources for future human activity on the Moon. 


\section{Simulated Robotic Follow-up Mission (2010)}

\section{A. Description}

From 19 July to 8 August 2010, we conducted a simulated robotic follow-up mission at Haughton Crater. Deployment of the K10 rovers to Haughton Crater started with cargo transport via Air National Guard C-130 Hercules flight from NASA Ames Research Center to Resolute Bay, Nunavut, Canada. Canada's Polar Continental Shelf Project (PCSP) carried cargo from Resolute Bay to Devon Island in a few Twin Otter flights. The field team comprised six members of the NASA Ames Intelligent Robotics Group on site at Haughton, and two geology students from Arizona State University.

At Haughton Crater, we set up local operations at the Haughton-Mars Project (HMP) Research Station ("base camp"). HMP provided C-band and Kaband satellite network communications from base camp to NASA Ames. We used a "Voice over IP" (VOIP) system to connect voice loops between NASA Ames and the field. We used a combination of a Tropos mesh Wi-Fi system and Wi-Max point-to-point wireless to connect the base camp network to the K10 robots at locations around the crater (Figure 23).

\section{B. Activities}

\section{Locale 8}

We began the robotic follow-up mission by operating at Locale 8 for three days. Locale 8 is located approximately $500 \mathrm{~m}$ north of base camp (Figure 22). Because of satellite network problems, we conducted remote operations with a small "ground control" team from base camp. We took care to ensure that this team's knowledge of Locale 8 was based only on field notes and briefings from the 2009 crew mission and general relevant literature (e.g., impact crater processes). The local science team did not visit the site in person.

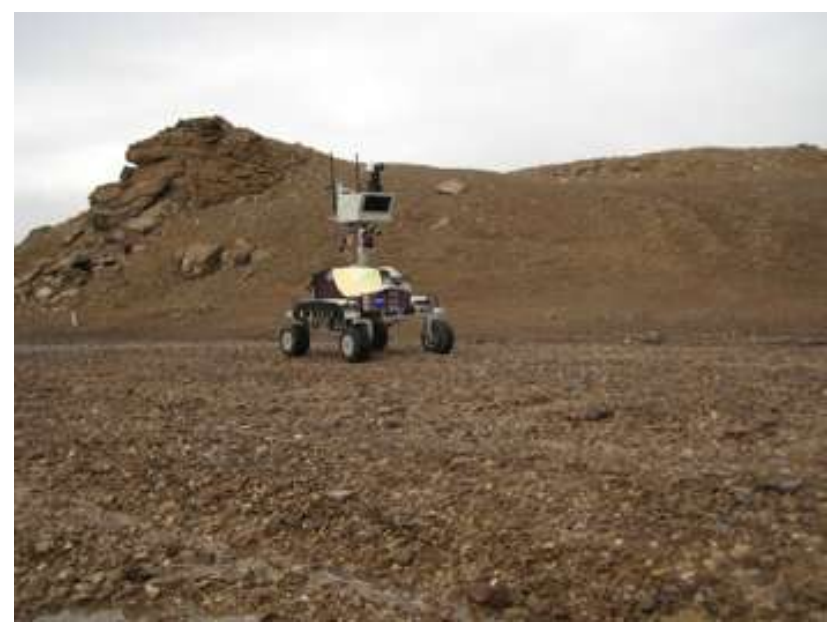

Figure 24. K10 operating at Locale 8.

The primary science objective at Locale 8 was to determine carbonate stratigraphy. However, due to miscommunication between different parts of the science team, the local ground control team initially focused robot field work on local scale stratigraphy, looking for evidence of exposed layers in the surrounding surface materials (Figure 24). Thus, K10 traverse plans included several transect surveys with $\mathrm{XRF}$ and MI measurements every two meters to try and identify differences in elemental composition or surface clasts.

After several hours of remote robot operations, it was clarified that the main objective at Locale 8 was to identify stratigraphy that might be apparent in the surrounding ridges and buttes. These observations are best captured by looking out at the horizon with high resolution remote imaging (PanCam and Lidar). The science data collected during the XRF/MI transects were very informative, but the key lesson learned was the need for good transfer of knowledge between the EVA crew and the team conducting the robotic follow-up for that EVA. It also was apparent that the need for transects of repeated measurements could be greatly facilitated by some additions to our rover traverse planning tools. 

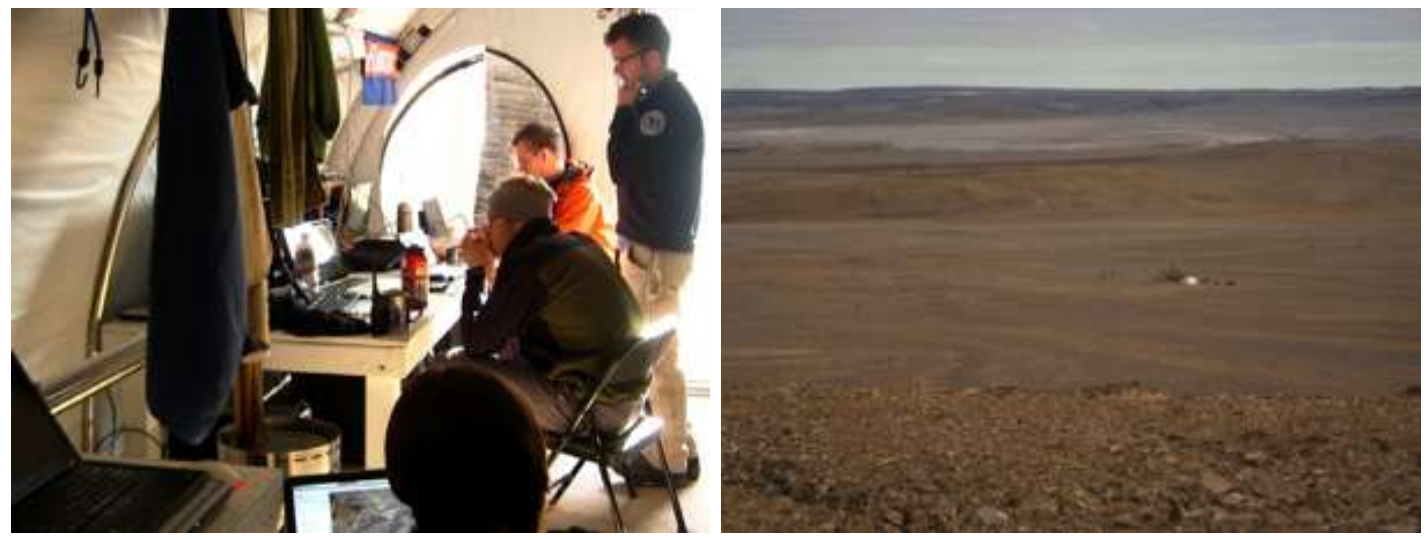

Figure 25. K10 operations at Haughton Crater. Left, the local "ground control" team worked from base camp. right, K10 operations at Site B.

Once work was completed at Locale 8, we moved K10 to Site B (Locales 1, 2 and 3) for four days of operations (Figure 25). Site B is located approximately $1 \mathrm{~km}$ southeast of base camp (Figure 22) inside Haughton Crater. Due to continued satellite link issues, we began remote operations with the local ground control team at base camp. However, even the surface wireless link from base camp to K10 proved difficult to maintain. Ultimately, the local science team (at base camp) created a series of plans for the areas of interest, and we operated K10 from a temporary tent erected near Locale 2. The science data collected from these plans was then brought back to the local science team for review. The local science team visited the site in person only after the K10 work was completed at Site B.

The two primary science objectives at Site B were to: (1) determine the distribution of ground ice on the rim, slope, and low-lying areas around Site B; and (2) ascertain whether the large boulders that are visible in the QuickBird satellite orthophoto were down-faulted from the rim, or emplaced ejecta blocks thrown from the crater. These two objectives were addressed by planning traverses with high resolution PanCam and Lidar imaging of the boulders and GPR transects along the rim, down the slope, and across the region between Locales 1, 2, and 3 .

\section{Locale 9}

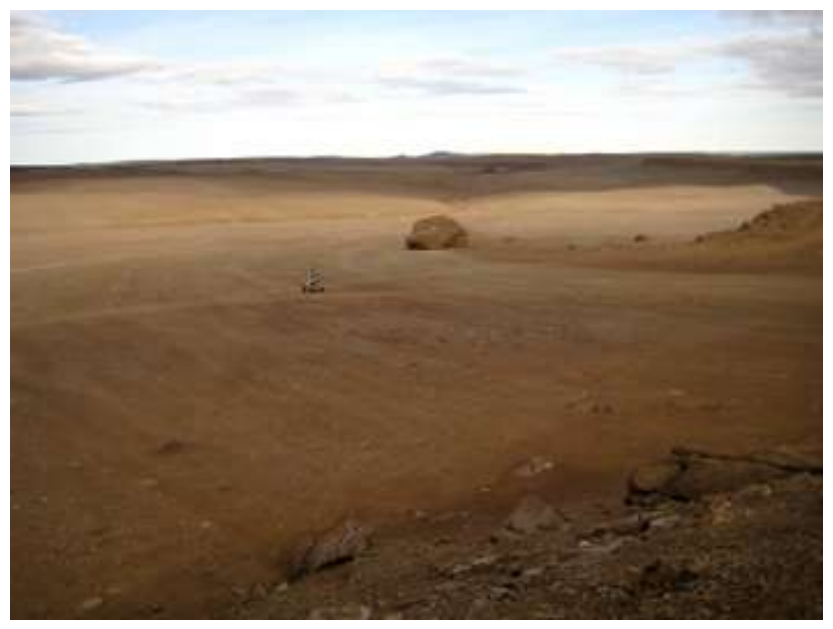

Figure 26. K10 operating at Locale 9 near HMP base camp.

Following Site B, we relocated robot operations to Locale 9 (Figure 26) for two days of robotic follow-up. Locale 9 is located approximately 400 m northwest of base camp (Figure 22). Although the satellite link had been established by this time, the link quality was highly variable. Thus, we began remote operations with ground control located at base camp before switching to ground control (Figure 27) at NASA Ames. 

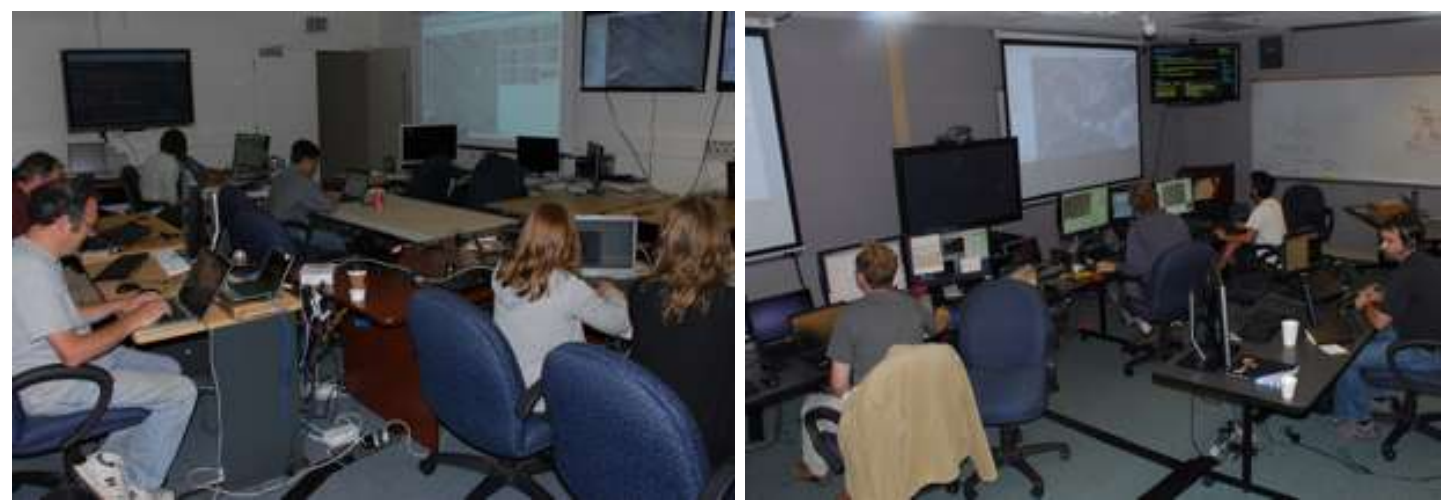

Figure 27. The ground control team at NASA Ames Research Center.Left, the Science Operations team developed robot activity plans and analyzed data acquired by the K10 robot; right, the Flight Control team performed tactical operations.

The primary science objective at Locale 9 was to investigate the origin of the polygon features. K10 traverses focused on mapping the distribution of ground ice using GPR and making surface observations with MI and Lidar. During remote operations, it was determined that K10's position estimator was somewhat unreliable, particularly with respect to orientation. Consequently, the ground control team at NASA Ames adopted a landmark-based navigation strategy in order to drive linear transects.

\section{Locale 7}

We next moved K10 to Locale 7 for the final part of the follow-up mission. Locale 7 is located approximately $2 \mathrm{~km}$ northwest of base camp (Figure 22). Over three days, we conducted K10 remote operations with a full ground control team at NASA Ames. During this period, the communication link between K10 and ground control provided 1-1.5 Mbps bandwidth with approx. 600 msec round-trip delay.

The primary science objectives at Locale 7 were to look for carbonate stratigraphy in the ridge below Locale 7. Observing the layers and blocks on the side of the ridge required access to the "shelf" below the ridge, which was a broad and relatively flat area situated topographically between the base of "Von Braun Planitia" and the top of the ridge. K10 remote operations included PanCam and Lidar observations of the ridge from Von Braun, as well as multiple attempts to find a way up to the lower shelf.
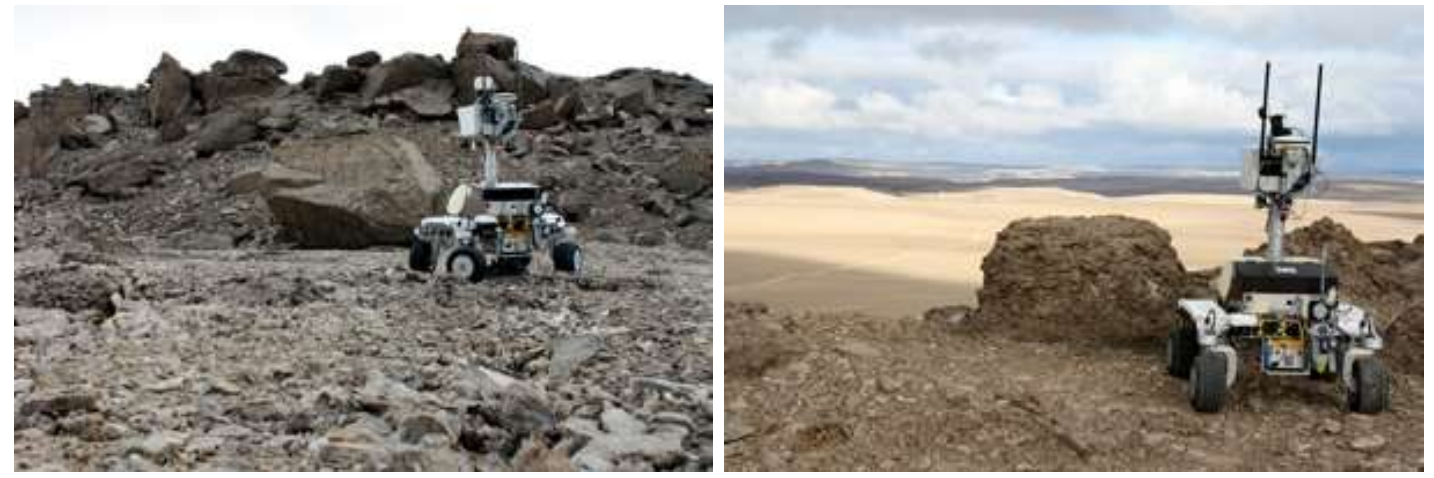

Figure 28. K10 operating at Locale 7. Left, negotiating a heavily bouldered section of the lower shelf; right, acquiring PanCam images from the ridge line.

With only limited time available for the mission simulation, we chose to accelerate the field test by pausing the simulation, manually transporting K10 to the shelf, and then resuming science operations to the ridge (Figure 28). PanCam and Lidar measurements taken from viewpoints on the shelf greatly improved the science team's ability to investigate the structure and possible layering in the carbonates of the ridge.

The problems that ground control had driving K10 up the shelf point out two key issues: (1) the difficulty inherent in identifying trafficable areas using only satellite imaging and low-resolution topographic maps; and (2) the need to be able to use K10's science instruments for tactical operations. For example, the ground control team might have been able to find a navigable route if they had been able to use the Lidar for remote driving, in addition to its function as a science instrument. 


\section{Results}

\section{A. Science}

\section{Geologic Mapping}

At Site A, one of our objectives was to use PanCam images to test, verify, and amend the geologic map developed by the crew mission. Of the PanCam images that were taken by K10 at Site A, seven provided useful views of the marker beds in the host carbonate stratigraphy. We analyzed two of these images and compared them to Quickbird satellite orthophotos to determine marker bed continuity and possible fault offset (Figure 29). The results are mixed. In a number of places the PanCam images appear to support initial interpretations, or are sufficient for re-interpretation of the map. In other locations, however, the data acquired by K10 is not informative enough to verify (or amend) the existing geologic map.

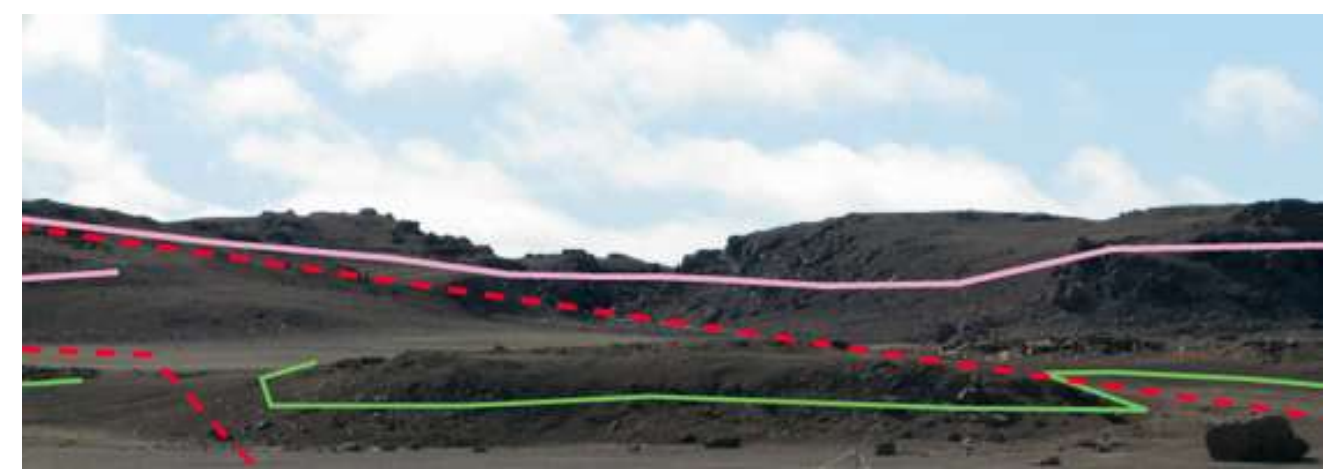

Figure 29. PanCam image looking SW from Locale 8. Green and pink represent marker beds. Red dashed lines represent possible faults.

At Site B, the gently sloping northwest crater wall below the crater rim was observed during the crew mission to be composed of unconsolidated carbonate rubble: angular pebble- to cobbled-size clasts of dark to light brown dolostone similar to the target rock carbonate exposed at the crater rim. Low relief mounds, ledges and benches (observed with binoculars and visible in Quickbird imagery) comprise local topographic highs on this otherwise gentle and uniform slope. This rubble zone is a significant feature of the crater, a concentric ring of material that lies between the crater rim and a zone mapped as "dolomite slabs and blocks" which is, in turn, marginal to the white calcite breccias and melt sheet of the crater interior.

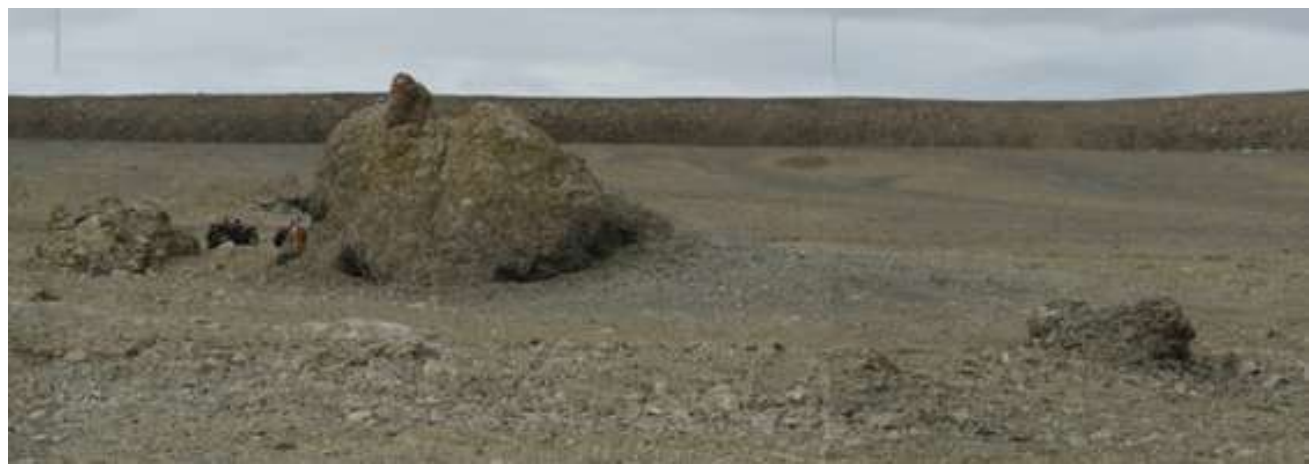

Figure 30. K10 PanCam image of an approx. 5x15 m rounded block of breccia. The texture, setting and composition is consistent with impact emplacement.

Robotic follow-up at Site B focused on addressing the origin of this carbonate rubble zone and of the local topographic highs within it. Data collected by K10 were used to evaluate four hypotheses, none of which were mutually exclusive. PanCam imagery of the northwest crater wall acquired by K10 supports a preliminary interpretation that the crater wall, though highly degraded, preserves evidence of fault-bounded terraces formed after impact as the crater rim collapsed inward. The images also show that the crater wall is also the site of at least one breccia block (Figure 30) that is likely impact ejecta. The origin of this block remains unclear. It is either resting in a position that records ballistic emplacement or was emplaced by ice rafting from an indeterminate locale. 


\section{Geophysical Survey}

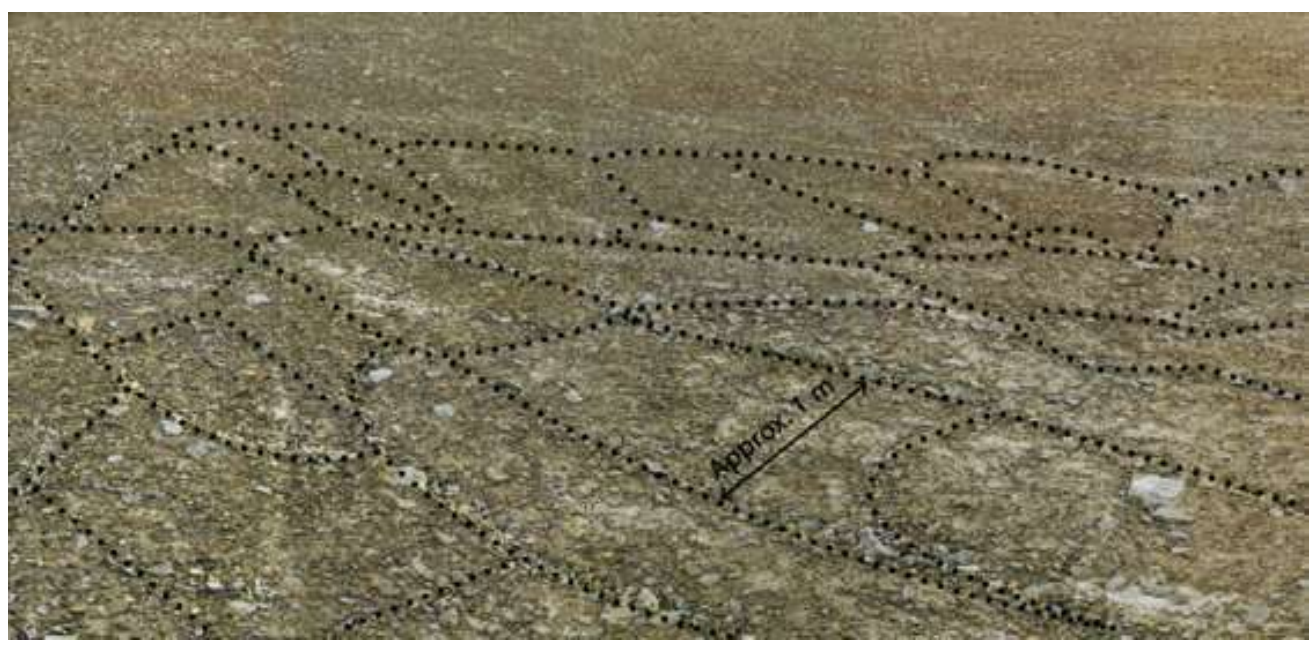

Figure 31. K10 PanCam image from Locale 9 shows distinct presence of polygons. This image was correlated with GPR and Lidar data to assess the depth and amount of subsurface ice below this zone.

At Site A, we used a combination of K10's instruments to study the polygon features. Data from the MI and PanCam data were used to determine the surface roughness characteristics, grain sizes, and compositions of surface materials. Lidar was used to observe 3D surface features, particularly crack edges. GPR was used to map the depth to the ice layer (thickness of the active layer) in the area. Based on the data collected, we were able to determine that the average depth to the top of the ice layer is approximately $1 \mathrm{~m}$ (Figure 31).
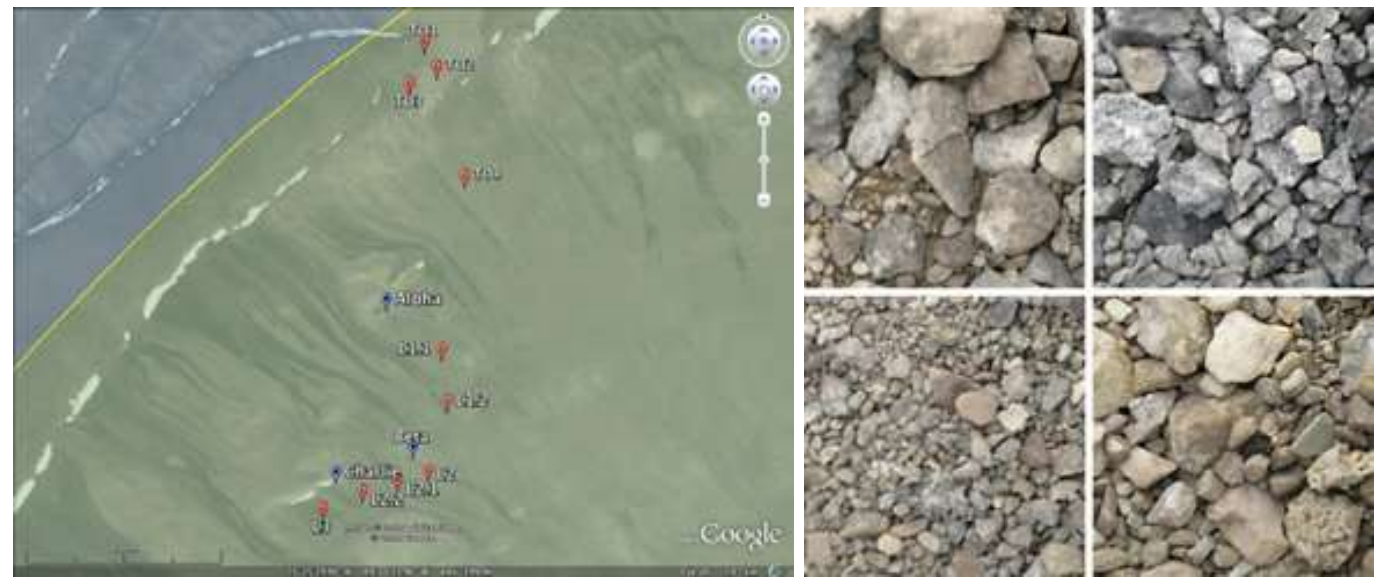

Figure 32. Site B observations were made near the NW crater wall. Left, map showing locations (red icons) where K10 acquired data and the crater rim (yellow line); right, MI images acquired at Locale 1.

At Site B (Figure 32), we used K10 to study the gullies along the northwest crater wall. MI data acquired at Locale 1 revealed thermally derived, poorly sorted angular rocks ranging from a few $\mathrm{cm}$ to $5 \mathrm{~mm}$ in size. Alluvium is the dominant feature, indicating material transport by ice melt. PanCam images taken at Locale 2 showed signs of polygonal features in the soil. The random shape, size, and orientation of the polygons suggest the presence of subsurface ice. PanCam images of Locale 3 present a surface that is fairly smooth, characterized by alternating bands of dark and light material. The parallel nature of these bands may suggest the presence of a receding shoreline from an overlying ice or liquid water layer.

Considering the long-term presence of the gullies and observations of polygons with randomly oriented borders, we are able to conclude that subsurface ice is the most likely mechanism for polygon formation at Haughton Crater. 


\section{B. Discussion}

Based on our field testing, we have confirmed several key differences between robotic exploration (e.g., as done by the Mars Exploration Rovers) and robotic follow-up. Most notably, whereas robot explorers serve as principal science tools, the primary function of robotic follow-up is to augment and complete human field work. This has significant implications for mission design and science operations.

From our 2010 robotic mission simulation, we learned that robotic follow-up can be useful for geological mapping. In particular, we found that K10 enabled us to further evaluate the structure of the inner wall of Haughton Crater, to map faults/fractures in rocks proximal to the crater rim, and to better understand the target sequence stratigraphy. For geophysical survey applications, we learned that robotic follow-up can provide precise metrics for quantifying the volumes, depths, concentration, and large-scale distributions of subsurface ice.

There are, however, several important considerations to keep in mind. First, in order for robotic follow-up to be effective, it is essential that there be good coordination between the work that humans and robots each perform in the field. Specifically, the efficiency, productivity, and benefit of robotic follow-up is highly coupled to the robot's mobility and instrument capabilities. Crew mission planning, therefore, needs to consider not only what humans will do (e.g., in EVA), but also what subsequent robots will be able to do.

Second, accurate and consistent localization (particularly orientation) is needed to co-register data acquired by orbital remote sensing, human surface missions, and robotic follow-up. Although position estimates with limited accuracy (or even significant errors) can often be rectified through post-processing, interactive exploration missions will need real-time positioning that can be used by humans and robots alike.

Third, we have found that orbital remote sensing, human field work and robot follow-up are highly complementary. Each of these provides different types of data, viewpoints, and resolution. Individually none of these exploration methods is fully adequate or sufficient to fully explore planetary surfaces. However, by using all three methods in combination, we can improve the coverage, completeness, and quality of observations and measurements.

Overall, though development of human-robot science protocols and field procedures is still in its infancy, this experiment demonstrates the exceptional promise of robotic follow-up to human exploration as a planetary exploration field technique. Our initial results indicate that robotic follow-up is well suited to: (1) testing of hypotheses generated during time-limited human fieldwork and subsequent analysis; (2) refining and augmenting data gathered during crew traverses and EVAs; (3) rote or long-duration data collection (e.g. Lidar, GPR, etc.) tasks. Future work will seek to further confirm and quantify these benefits.

\section{Acknowledgments}

We thank Kira Lorber, Steve Braham, and the Mars Institute for providing field test support. We also thank Rachel Hoover, Estelle Dodson, Anthony Chan, and the NASA Lunar Science Institute for supporting outreach activities. Finally, we especially thank Hamilton Sundstrand for providing concept space suits and the NASA Johnson Space Center Mission Operations Directorate (Codes DO and DX) for their help in conducting the robotic mission simulation. This work was sponsored by the NASA Moon and Mars Analog Mission Activities (MMAMA) Program. The NASA Exploration Technology Development Program and Exploration Analog Missions provided support.

\section{References}

${ }^{1}$ Fong, T., Bualat, M., et al., "Field testing of utility robots for lunar surface operations," Space, No. AIAA-2008-7886, AIAA, 2009.

${ }^{2}$ Hodges, K. and Schmitt, H. H., "A new paradigm for advanced planetary analog exploration exercises on Earth," Geologic Society of America Special Paper: Analogs, 2010. 2007.

${ }^{3}$ National Research Council, The scientific context for exploration of the Moon: final report, National Academies Press,

${ }^{4}$ NASA Advisory Council, "Workshop on science associated with the lunar exploration architecture," Tech. Rep. NP-200808-542-HQ, NASA, 2008.

${ }^{5}$ International Space Exploration Coordination Group, "Global Exploration Strategy," Tech. rep., International Space Exploration Coordination Group, 2009.

${ }^{6}$ Bualat, M., Edwards, L., et al., "Autonomous robotic inspection for lunar surface operations," Field and Service Robots, Springer, 2007. 
${ }^{7}$ Fong, T., Allan, M., et al., "Robotic site survey at Haughton Crater," 9th International Symposium on Artificial Intelligence, Robotics, and Automation in Space, 2008.

${ }^{8}$ Deans, M., Fong, T., et al., "Robotic scouting for human exploration," Space, No. AIAA-2009-6781, AIAA, 2009.

${ }^{9}$ Fong, T., Abercromby, A., et al., "Assessment of robotic recon for human exploration of the Moon," Acta Astronautica, 2010.

${ }^{10}$ Gernhardt, M., Abercromby, A., et al., "Engineering evaluation of Lunar Electric Rover 1B and Portable Utility Pallet during simulated planetary surface exploration," Tech. rep., NASA Johnson Space Center, 2009.

${ }^{11}$ Bualat, M., Kobayashi, L., Lee, S., and Park, E., "Flexible rover architecture for science instrument integration and testing," Space, AIAA, 2006.

${ }^{12}$ Flückiger, L., To, V., and Utz, H., "Service oriented robotic architecture supporting a lunar analog test," International Symposium on Artificial Intelligence, Robotics, and Automation in Space, 2008.

${ }^{13}$ Mishkin, A., Lee, Y., et al., "Human-robotic missions to the Moon and Mars: operations design implications," Aerospace Conference, IEEE, 2007.

${ }^{14}$ Aghevli, A., Bachmann, A., et al., "Planning applications for three Mars missions with Ensemble," International Workshop on Planning and Scheduling for Space, 2007.

${ }^{15}$ Torres, R., Allan, M., et al., "RAPID: Collaboration results from three NASA centers in commanding/monitoring lunar assets," Aerospace Conference, IEEE, 2009.

${ }^{16}$ Schreckenghost, D., Fong, T., et al., "Real-time assessment of robot performance during remote exploration operations," Aerospace Conference, IEEE, 2009.

${ }^{17}$ Schreckenghost, D., Fong, T., et al., "Measuring robot performance in real-time for NASA robotic reconnaissance operations," Performance Metrics for Intelligent Systems, NIST, 2009. 